\title{
Article \\ Insights into the Stability and Activity of MIL-53(Fe) in Solar Photocatalytic Oxidation Processes in Water
}

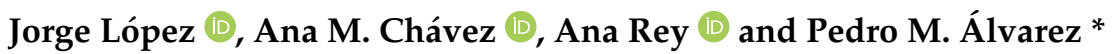 \\ Departamento de Ingeniería Química y Química Física, Instituto Universitario de Investigación del Agua, \\ Cambio Climático y Sostenibilidad (IACYS), Universidad de Extremadura, Avd de Elvas s/n, \\ 06006 Badajoz, Spain; jorgelg@unex.es (J.L.); amchavez@unex.es (A.M.C.); anarey@unex.es (A.R.) \\ * Correspondence: pmalvare@unex.es
}

check for updates

Citation: López, J.; Chávez, A.M.; Rey, A.; Álvarez, P.M. Insights into the Stability and Activity of MIL-53(Fe) in Solar Photocatalytic Oxidation Processes in Water. Catalysts 2021, 11, 448. https:// doi.org/10.3390/catal11040448

Academic Editor: Weilin Dai

Received: 9 March 2021

Accepted: 27 March 2021

Published: 30 March 2021

Publisher's Note: MDPI stays neutral with regard to jurisdictional claims in published maps and institutional affiliations.

Copyright: (C) 2021 by the authors. Licensee MDPI, Basel, Switzerland. This article is an open access article distributed under the terms and conditions of the Creative Commons Attribution (CC BY) license (https:// creativecommons.org/licenses/by/ $4.0 /)$.
Abstract: MIL-53(Fe) is a metal organic framework that has been recently considered a heterogeneous photocatalyst candidate for the degradation of water pollutants under visible or solar radiation, though stability studies are rather scarce in the literature. In this work, MIL-53(Fe) was successfully synthesized by a solvothermal method and fully characterized by X-ray diffraction (XRD), attenuated total reflectance Fourier transform infrared spectroscopy (ATR-FTIR), $\mathrm{N}_{2}$ adsorption-desorption isotherm, Thermogravimetric analysis coupled with mass spectrometry (TGA-MS), UV-visible diffuse reflectance spectroscopy (DRS), elemental analysis and wavelength dispersive $X$-ray fluorescence (WDXRF). The effects of $\mathrm{pH}$, temperature, solar radiation and the presence of oxidants (i.e., electron acceptors) such as ozone, persulfate and hydrogen peroxide on the stability of MIL-53(Fe) in water were investigated. The as-synthetized MIL-53(Fe) exhibited relatively good stability in water at $\mathrm{pH}$ 4 but suffered fast hydrolysis at alkaline conditions. At pH 4-5, temperature, radiation (solar and visible radiation) and oxidants exerted negative effect on the stability of the metal-organic framework (MOF) in water, resulting in non-negligible amounts of metal (iron) and linker (terephthalic acid, $\mathrm{H}_{2} \mathrm{BDC}$ ) leached out from MIL-53(Fe). The photocatalytic activity of MIL-53(Fe) under simulated solar radiation was studied using phenol and metoprolol as target pollutants. MIL-53(Fe) on its own removed less than $10 \%$ of the pollutants after $3 \mathrm{~h}$ of irradiation, while in the presence of ozone, persulfate or hydrogen peroxide, complete elimination of pollutants was achieved within $2 \mathrm{~h}$ of exposure to radiation. However, the presence of oxidants and the formation of some reaction intermediates (e.g., short-chain carboxylic acids) accelerated MIL-53(Fe) decarboxylation. The findings of this work suggest that MIL-53(Fe) should not be recommended as a heterogeneous photocatalyst for water treatment before carrying out a careful evaluation of its stability under actual reaction conditions.

Keywords: catalyst stability; metal organic frameworks; MIL-53(Fe); photocatalysis; solar radiation; water treatment

\section{Introduction}

Advanced oxidation processes (AOPs) have been extensively used for the degradation of organic pollutants in water. In these processes, combinations of oxidants, catalysts and/or radiation of different wavelengths produce powerful secondary oxidizing species (e.g., free radicals such as hydroxyl radical, $\mathrm{HO}^{\bullet}$ ), which can even mineralize organic contaminants. In the last decades, a great deal of research on AOPs has been devoted to photocatalytic processes mediated by solar radiation or low-cost energy sources (e.g., visible LED lamps) seeking for cleaner, more efficient and economically viable processes [1]. Efforts have been focused on developing new visible-light-responsive photocatalysts for the removal of contaminants from water with improved properties such as high adsorption capacity and photocatalytic activity under solar radiation or visible light, easy post-recovery and reusability. In this sense, some types of the so-called metal-organic frameworks (MOFs) are arising growing interest as potential heterogeneous photocatalysts [2]. 
MOFs constitute a new class of porous, crystalline materials formed by an extended network of metal ions (clusters) coordinated to multifunctional organic ligands (linkers) through coordination bonds. The combination of inorganic and organic units in the MOF offers an outstanding number of structural possibilities for materials with predefined properties that might make them useful in a variety of applications such as gas storage and separation, molecular sensing, catalysis or drug delivery [3]. Since 2007, when Llabrés i Xamena and co-workers showed the photocatalytic activity of MOF- 5 for the degradation of phenol [4], an increasing number of MOFs have been researched as photocatalysts for the degradation of organic pollutants in water [5-7]. Particularly appealing in this field are Fe-based MOFs, which can absorb visible light due to the direct excitation of iron-oxo clusters [8]. Furthermore, they can work as heterogeneous catalysts for the activation of hydrogen peroxide (e.g., Fenton-like reactions) [9-11], persulfate [12,13] or ozone [14]. Among the Fe-based MOFs, MIL-53(Fe), a three-dimensional, flexible, porous solid composed of $\mathrm{FeO}_{4}(\mathrm{OH})_{2}$ octahedra clusters connected by 1,4-benzenedicarboxylate (BDC) linkers, has gained special attention in the recent literature as a potential visible-light photocatalyst for the degradation of organic pollutants in water (Table S1) [15-44]. MIL-53(Fe) offers the advantages of easy preparation from terephthalic acid and common iron salts, stability, non-toxicity and good visible light absorption [15]. As shown in Table S1, the photocatalytic activity of MIL-53(Fe) has been mainly demonstrated in the decolorization of dyes, such as methylene blue, rhodamine B or acid orange 7 , though there are also studies about the photodegradation of other types of pollutants like some pharmaceuticals and herbicides and on the photocatalytic reduction of $\mathrm{Cr}(\mathrm{VI})$ to $\mathrm{Cr}(\mathrm{III})[21,32,45-47]$. It has been reported that MIL-53(Fe) mediated photodegradation of organic pollutants takes place mainly through photogenerated holes $\left(\mathrm{h}^{+}\right)$and reactive oxygen species (ROS) such as singlet oxygen $\left({ }^{1} \mathrm{O}_{2}\right)$, superoxide radical $\left({ }^{\bullet} \mathrm{O}_{2}{ }^{-}\right)$and, especially, hydroxyl radical $\left(\mathrm{HO}^{\bullet}\right)$ [48]. However, as a general rule, photodegradation of organic contaminants mediated by bare MIL-53(Fe) is a rather slow process due to fast electron-hole recombination, though this can be prevented to some extent by controlling the $\mathrm{Fe}$ (II)/ $\mathrm{Fe}$ (III) ratio in the MOF structure [49]. The photocatalytic performance of MIL-53(Fe) can be enhanced in hybrid materials [17-19,22,25-28,32,34,35,37-41,43,44], by acid modulation [36] and/or using electron acceptors, such as hydrogen peroxide [15,16,18-20,23,40,43], persulfate [15,24,35,42], percarbonate/Fe(III) [30] or peroxymonosulfate [31]. Contrarily, little information is found in the available literature regarding the use of ozone in photodegradation processes catalyzed by MIL-53(Fe) or other MOFs despite some Fe-based MOFs having been recently reported as useful catalysts for the ozonation of rhodamine B and salicylic acid $[14,50]$. The studies carried out so far on the photodegradation of aqueous pollutants by MIL-53(Fe) have been mainly focused on the characterization and photocatalytic activity of the materials. However, much less attention has been paid to the stability of the MOF under the oxidizing photocatalytic environment. Some authors claimed that MIL-53(Fe) is rather photostable after reusing a catalyst sample in some batch photodegradation cycles with minor loss of activity $[15,16,21,23,24,31]$ while others observed a from moderate to serious decrease in the photocatalytic activity upon recycling [25-28,32,35,36]. In most of these works, results of FTIR and XRD revealed no significant changes in the chemical and crystal structure of the catalyst after recycling. However, from little to no information has been provided about iron leaching and stability of the linker (BDC) under photocatalytic conditions despite the fact that MIL-53(Fe) may decompose in water at a rate that depends on the $\mathrm{pH}$ and temperature of the media [51]. In addition, $\mathrm{H}_{2} \mathrm{BDC}$ is known to react fast with photochemically generated hydroxyl radical $\left(\mathrm{k}_{\mathrm{HO}} \bullet=4.4 \times 10^{9} \mathrm{M}^{-1} \mathrm{~s}^{-1}\right)$ [52]. Accordingly, during MIL-53(Fe)-mediated photocatalytic processes, the BDC linker could be at risk of photogenerated $\mathrm{HO}^{\bullet}$ attack, which might result in instability of the MOF. Recently, we have shown that the stability of other Fe-based MOF (MIL-100(Fe)) is a critical aspect to take into account before proposing it as a catalyst candidate for AOPs [53]. Therefore, it would be of interest to further investigate the stability of MIL-53(Fe) in order to explore its applications as photocatalyst in aqueous media. 
This study was conceived to evaluate the stability of MIL-53(Fe) in aqueous solution under typical conditions of solar photocatalytic oxidation. Thus, leaching of iron and organic matter from the MOF are evaluated at different process conditions. Photocatalytic activity of MIL-53(Fe) towards the degradation of phenol (Ph) and metropolol (MTP) in the presence of different electron acceptors (hydrogen peroxide, potassium persulfate and ozone) is also addressed.

\section{Results and Discussion}

\subsection{Characterization of MIL-53(Fe)}

Figure 1 shows the XRD patters of the pale-orange powder synthesized in this work and three simulated MIL-53s, designated as MIL-53(Fe)-ht (anhydrous), MIL-53(Fe)-int (metastable anhydrous phase) and MIL-53(Fe)-It (hydrated) [54]. Simulation was carried out using the Mercury program from the Cambridge Crystallographic Data Center (CCDC). As can be seen, XRD peaks of the synthesized material match well with those of the hydrated MIL-53(Fe)-It at $2 \theta$ of $9.2^{\circ}, 12.6^{\circ} ; 17.6^{\circ} ; 18.2^{\circ} ; 18.5^{\circ}$ and $25.4^{\circ}$. The recorded XRD pattern is also in good agreement with those obtained by other authors for MIL-53(Fe) materials with visible-light photocatalytic activity $[15,21]$ and/or ability to activate the decomposition of hydrogen peroxide [9], persulfate [11,13], peroxymonosulfate [31] or ozone [14] into ROS.

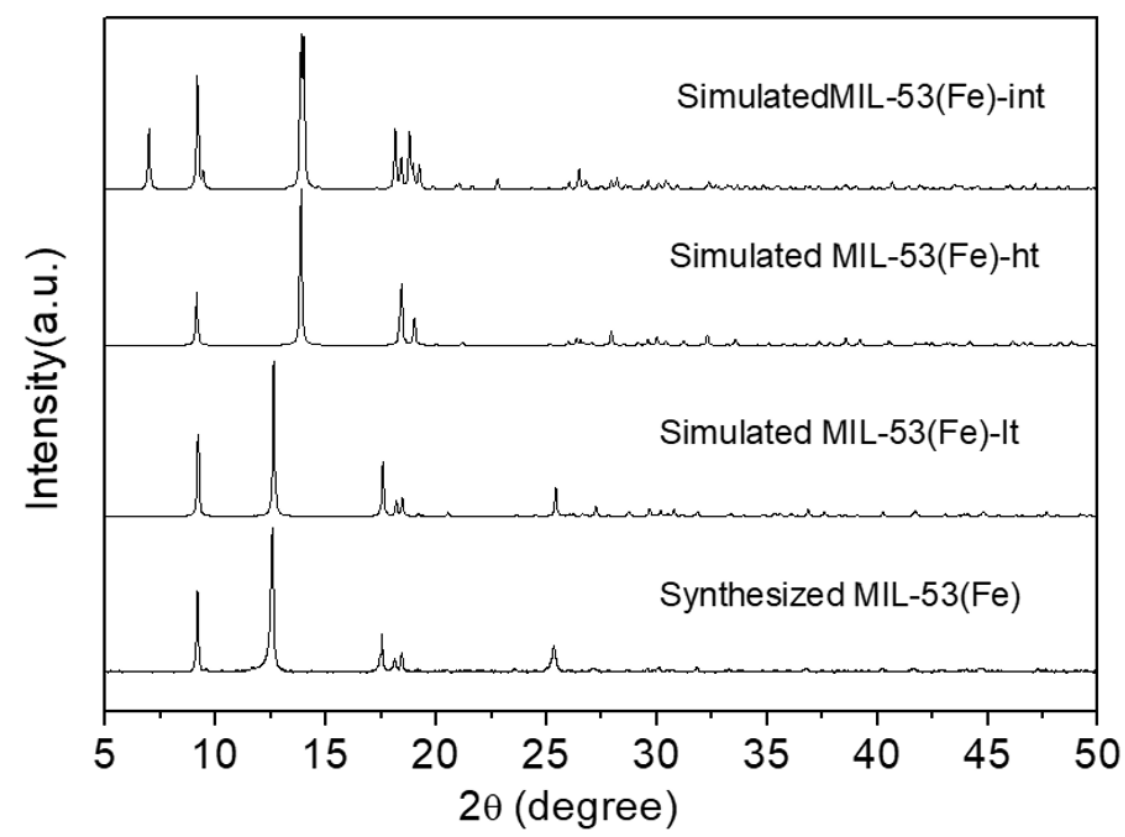

Figure 1. XRD patterns of the synthesized and three simulated MIL-53s.

The nitrogen adsorption-desorption isotherm of the as-synthesized MIL-53(Fe) is presented in Figure 2. It displays the profile of mixed type I and IV isotherms, typical of microporous and mesoporous materials, respectively. The specific BET surface area $\left(S_{\mathrm{BET}}=79 \mathrm{~m}^{2} \mathrm{~g}^{-1}\right)$ was obtained applying the BET equation to the section of the isotherm in the relative pressure range of $0.05-0.35$, the microporous volume $\left(\mathrm{V}_{\text {micro }}=0.012 \mathrm{~cm}^{3}\right.$ $\left.\mathrm{g}^{-1}\right)$ and external surface area $\left(S_{\text {ext }}=19 \mathrm{~m}^{2} \mathrm{~g}^{-1}\right)$ were calculated by the $\mathrm{t}$-plot method, and the total pore volume $\left(\mathrm{V}_{\mathrm{T}}=0.124 \mathrm{~cm}^{3} \mathrm{~g}^{-1}\right)$ was estimated as the volume corresponding to the branch of desorption of the isotherm at a relative pressure of 0.96 . In general, these values agree well with those reported in the literature for MIL-53(Fe), typically, with S and $V_{\mathrm{T}}$ in the $15-90 \mathrm{~m}^{2} \mathrm{~g}^{-1}$ and $0.01-0.3 \mathrm{~cm}^{3} \mathrm{~g}^{-1}$ ranges, respectively [13]. 


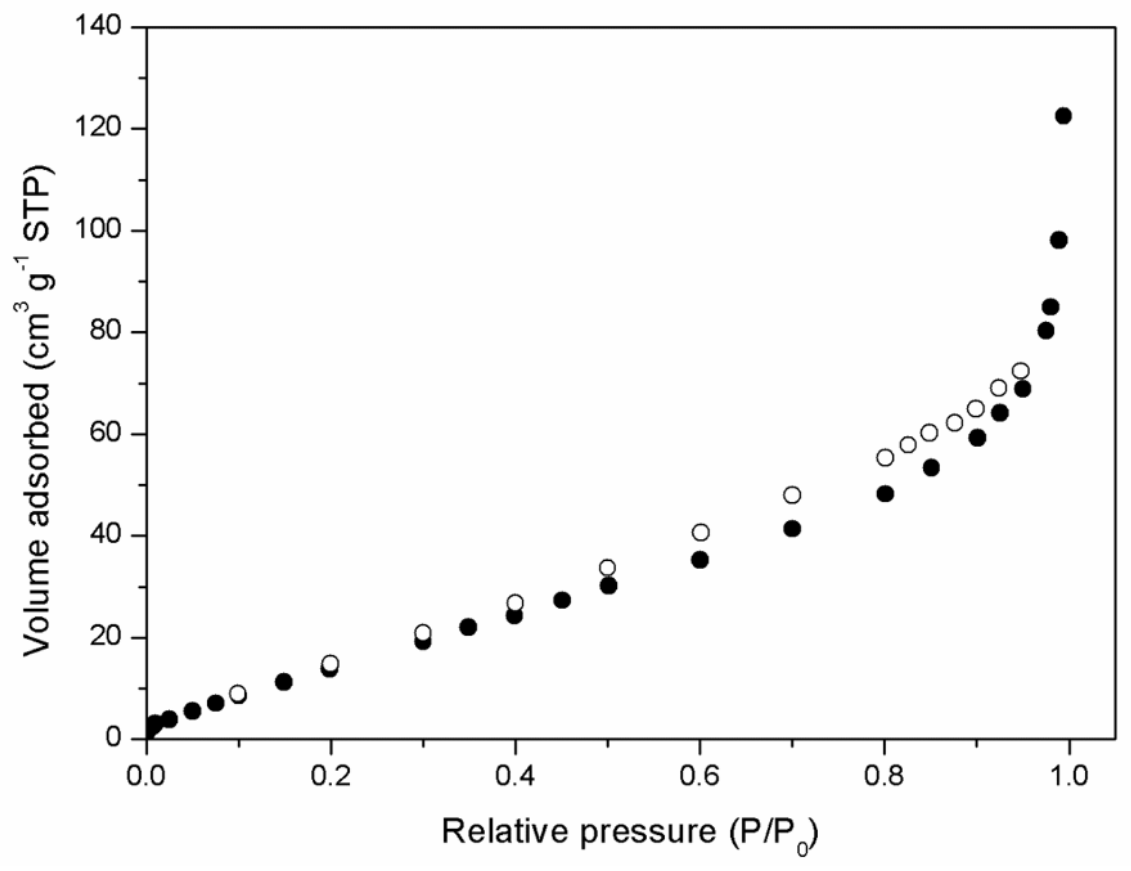

Figure 2. $\mathrm{N}_{2}$ adsorption-desorption isotherm at $-196{ }^{\circ} \mathrm{C}$ of the as-prepared MIL-53(Fe). Solid symbols: adsorption branch; Open symbols: desorption branch.

The morphology and particle size of the synthetized MIL-53(Fe) was evaluated by scanning electron microscopy (SEM). Figure 3 reveals well-defined rod-like particles at micrometric scale in addition to smaller bulky irregular fragments, which is in agreement with MIL-53(Fe) polycrystals synthetized under solvothermal conditions, according to previously reported studies [9].

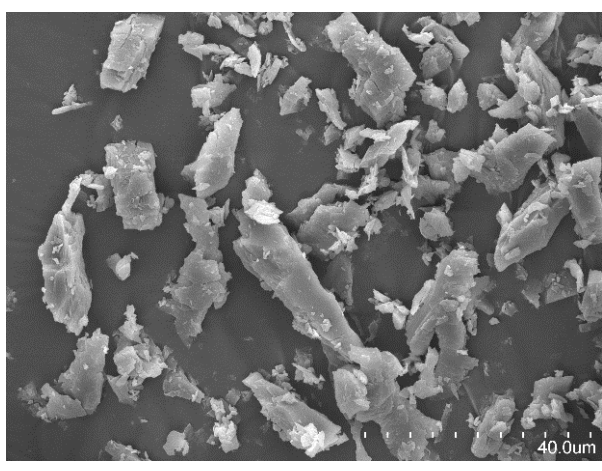

(a)

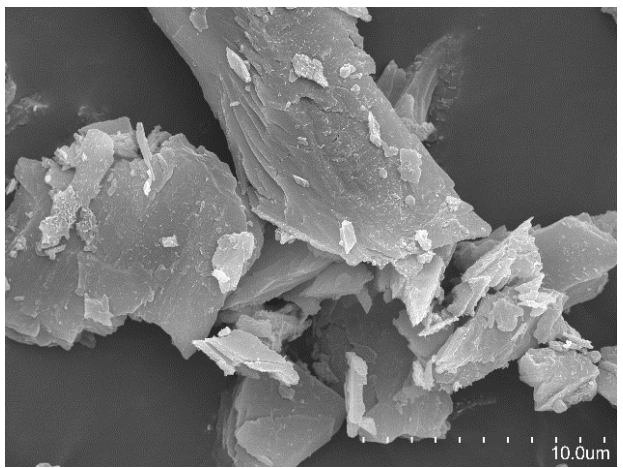

(c)

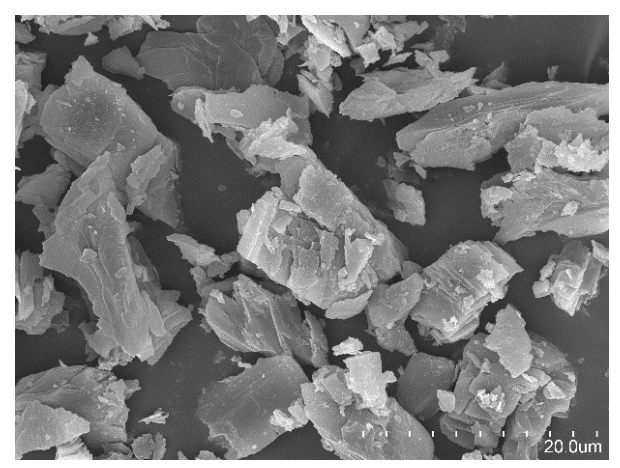

(b)

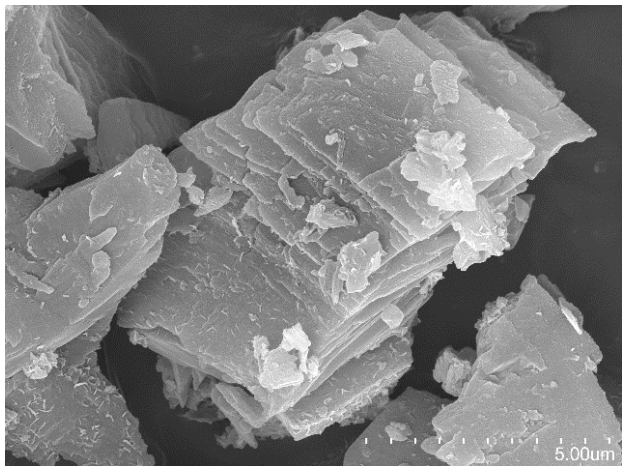

(d)

Figure 3. SEM images of the as-prepared MIL-53. Scale bar: (a) $40 \mu \mathrm{m}$; (b) $20 \mu \mathrm{m}$; (c) $10 \mu \mathrm{m}$; (d) $5 \mu \mathrm{m}$. 
Carbon and iron contents of the prepared MIL-53(Fe) were found to be $38.0 \mathrm{wt} \%$ and $21.2 \mathrm{wt} \%$, as determined by elemental analysis and wavelength dispersive $\mathrm{X}$-ray fluorescence (WDXRF), respectively, resulting in a Fe/C ratio of 0.558 , which is slightly lower than the theoretical 0.581 corresponding to pure MIL-53(Fe)-It (i.e., Fe $\mathrm{FII}^{\mathrm{II}}(\mathrm{OH})[\mathrm{BDC}] \cdot \mathrm{H}_{2} \mathrm{O}$ ). This suggests the presence of a small amount of free $\mathrm{H}_{2} \mathrm{BDC}$ trapped in the MOF structure (ca. $0.03 \mathrm{~g}$ free $\mathrm{H}_{2} \mathrm{BDC} / \mathrm{g}$ pure MIL-53(Fe)). The TGA profile presented in Figure 4 shows a small gradual decrease of mass up to ca. $150{ }^{\circ} \mathrm{C}$ due to the evaporation of adsorbed water $\left(<1 \%\right.$ weight) and a sharp weight loss in the temperature range of $350-440{ }^{\circ} \mathrm{C}$. This latter is primarily associated with dehydration of MIL-53(Fe) and combustion of the framework as deduced from the nature of evolved gases. Thus, the amount of carbon released as $\mathrm{CO}$ and $\mathrm{CO}_{2}$ accounted for $38.5 \mathrm{wt} \%$ of the initial mass, which is in close agreement with the elemental composition of the synthetized MOF. Moreover, the percentage of iron in the prepared MIL-53(Fe) estimated from the final residue of $\mathrm{Fe}_{2} \mathrm{O}_{3}$ was $21.0 \mathrm{wt} \%$, which is in agreement with WDXRF results.

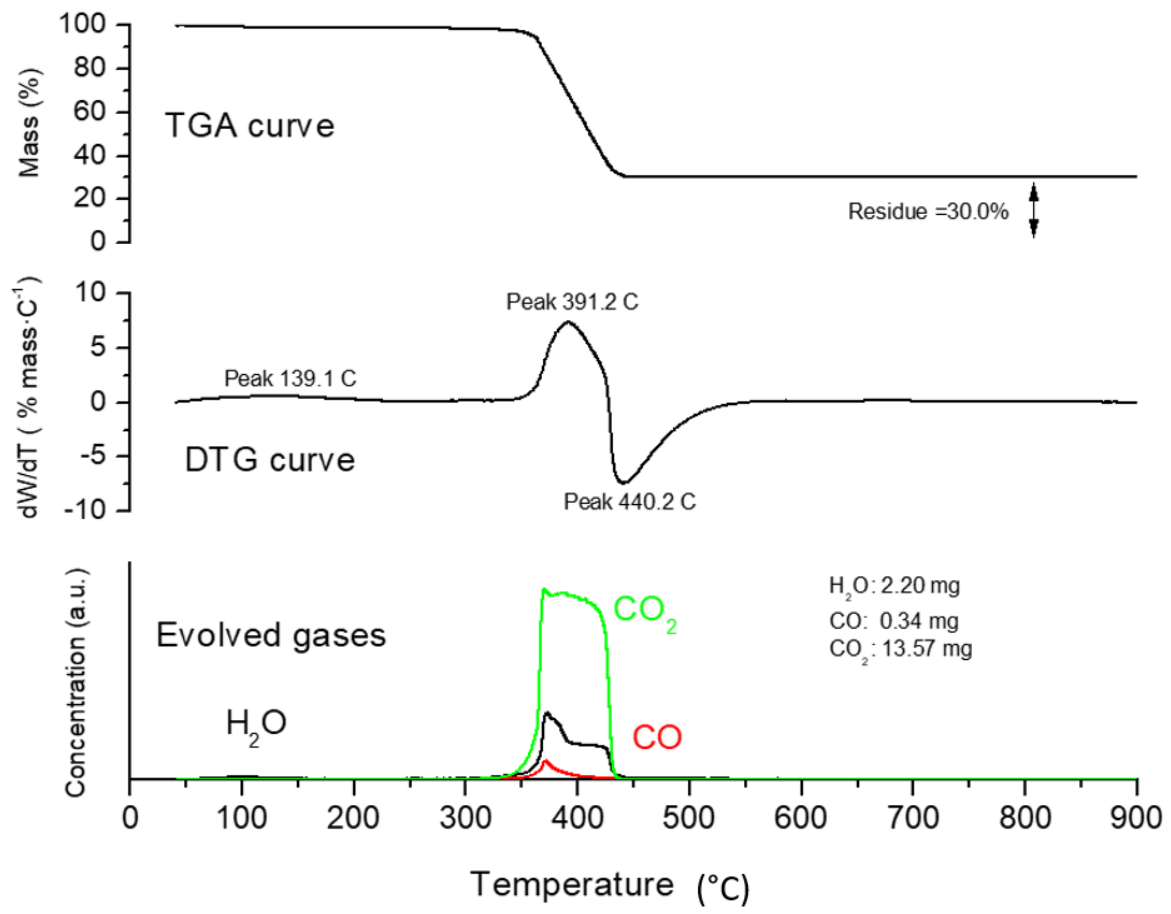

Figure 4. Thermal analysis of the as-prepared MIL-53(Fe).

Figure 5 shows the ATR-FTIR spectra of as-synthesized MIL-53(Fe) and $\mathrm{H}_{2} \mathrm{BDC}$ samples in the 500-2000 $\mathrm{cm}^{-1}$ wavenumber range. In accordance with previous studies, a number of characteristics peaks due to different surface groups can be distinguished in the spectrum of MIL-53(Fe) [21,30]. Thus, the band centered at $538 \mathrm{~cm}^{-1}$ corresponds to the stretching vibration of $\mathrm{Fe}-\mathrm{O}$ bonds between the carboxylic group of the ligand and $\mathrm{Fe}(\mathrm{III})$; the sharp peak at $747 \mathrm{~cm}^{-1}$ is due to the $\mathrm{C}-\mathrm{H}$ bending vibration of benzene rings of the linker; the broad bands centered at $1380 \mathrm{~cm}^{-1}$ and $1535 \mathrm{~cm}^{-1}$ are ascribable to symmetric and asymmetric stretching vibrations of $\mathrm{C}-\mathrm{O}$ bonds in carboxylic groups, respectively; the peak at $1632 \mathrm{~cm}^{-1}$ can be assigned to the $\mathrm{C}=\mathrm{O}$ stretching vibration of carboxylic groups. In addition, the weak peak at $1694 \mathrm{~cm}^{-1}$ could be tentatively ascribed to a slight shift of the $v(\mathrm{C}=\mathrm{O})$ vibration of carboxylic groups in free $\mathrm{H}_{2} \mathrm{BDC}$ occluded within the pores of MIL-53(Fe) [55]. 


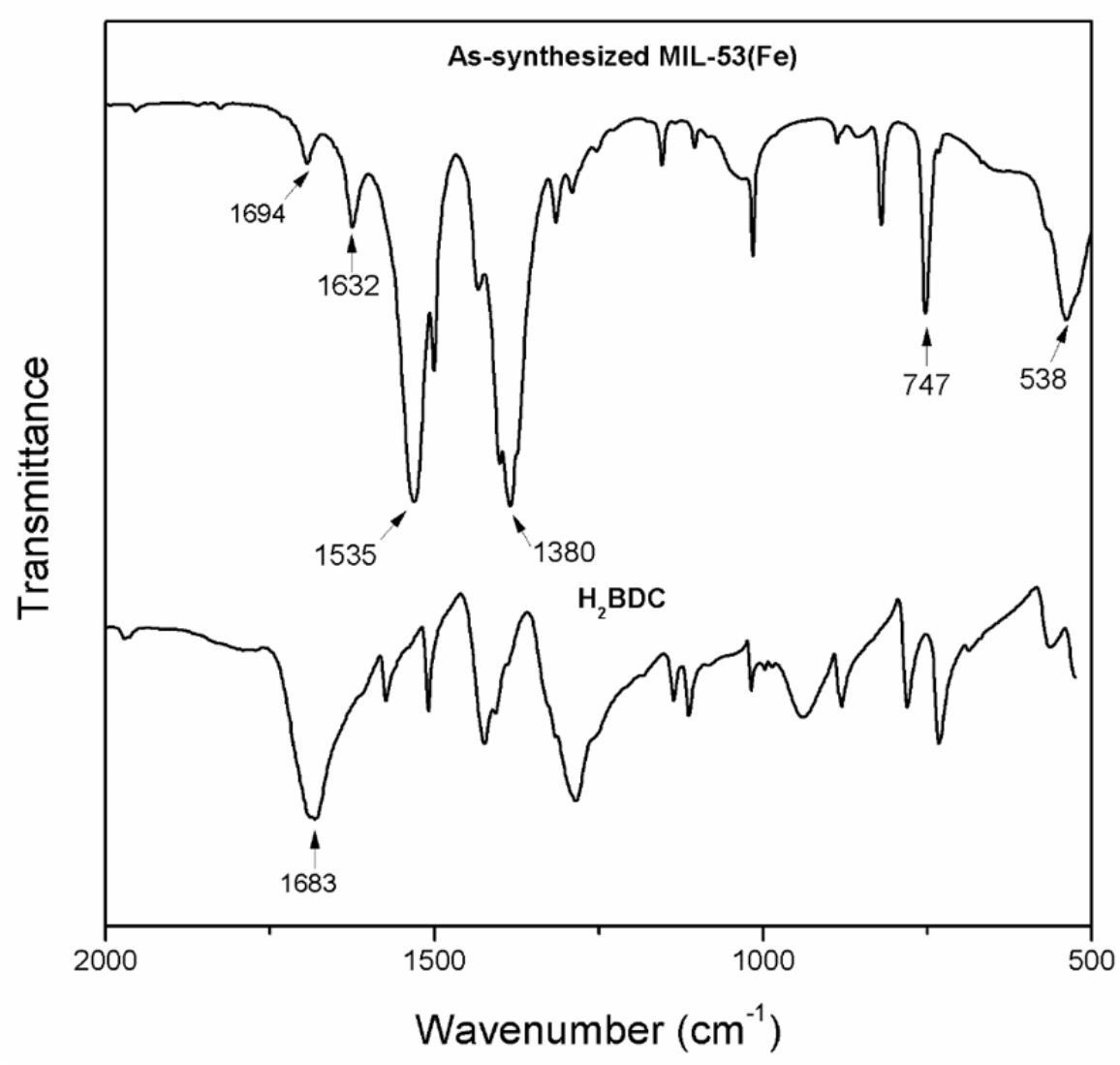

Figure 5. ATR-FTIR spectra of the as-synthesized MIL-53(Fe) and $\mathrm{H}_{2} \mathrm{BDC}$ samples.

The UV-visible diffuse reflectance spectroscopy (DRS) of the obtained MIL-53(Fe) shown in Figure 6 displays two main absorption bands at ca. $220 \mathrm{~nm}$ and $445 \mathrm{~nm}$, which can be ascribed to the ligand-to-metal charge transfer and to the spin-allowed d-d transition $\left({ }^{6} \mathrm{~A}_{1 \mathrm{~g}} \rightarrow{ }^{4} \mathrm{~A}_{1 \mathrm{~g}}+{ }^{4} \mathrm{E}_{\mathrm{g}}(\mathrm{G})\right)$ of octahedral Fe ${ }^{3+}$ in MIL-53(Fe) $[15,25,41]$. The optical band gap energy $\left(E_{g}\right)$ was estimated from a plot of $(\alpha \mathrm{hv})^{2}$ vs. the energy of absorbed light (inset of Figure 6) to be $2.7 \mathrm{eV}$, which reveals the ability of the MOF to harvest visible light. This $E_{\mathrm{g}}$ value agrees with most of the previous studies of optical properties of pure MIL53(Fe) $[15,18,20-23,25,27,28,32,34,40-42,46]$.

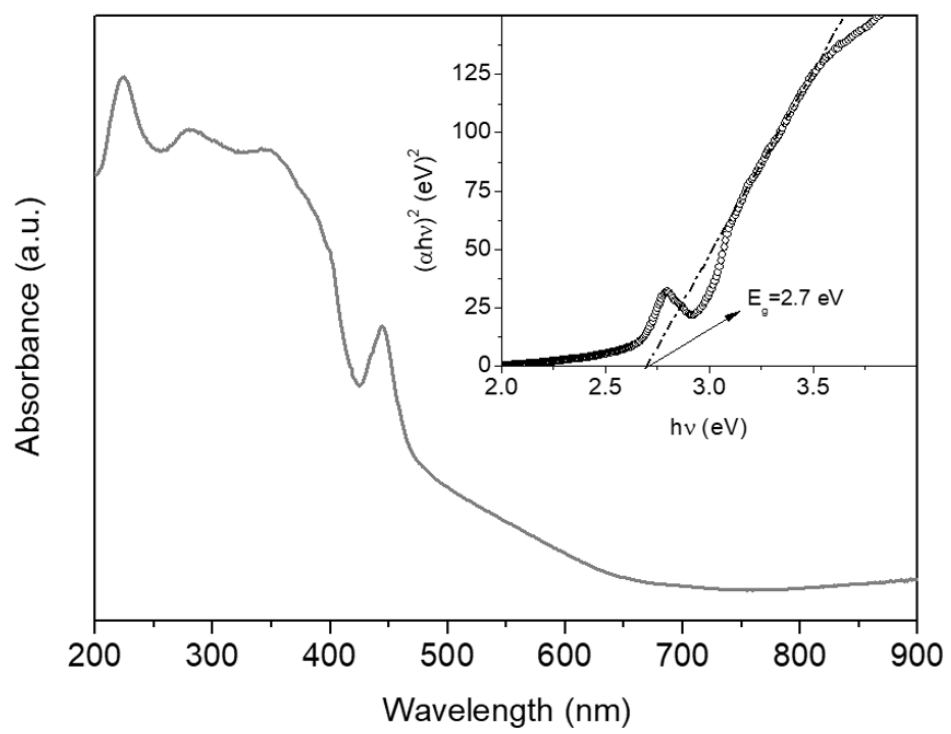

Figure 6. UV-vis diffuse reflectance spectrum of the as-prepared MIL-53(Fe). 
Based on the characterization data shown above, which are in good agreement with the literature on the MIL-53 (Fe) framework, it can be concluded that MIL-53(Fe) was successfully synthesized, though some free $\mathrm{H}_{2} \mathrm{BDC}$ remained clogged in the pore network of the MOF.

\subsection{Stability of MIL-53(Fe) in Water; Effect of $\mathrm{pH}$, Radiation and Presence of Oxidants}

MIL-53(Fe) has been generally considered to be an iron-carboxylate framework with appreciable stability in water. Consequently, this MOF has been investigated in adsorption and photocatalytic degradation of aqueous pollutants $[6,7,56]$. However, it has also been observed that MIL-53(Fe) may undergo hydrolysis to some extent in deionized water at $50^{\circ} \mathrm{C}$ and in a controlled $\mathrm{pH}=7$ aqueous solution at ambient temperature, according to Equation (1) [51]:

$$
2 \mathrm{Fe}(\mathrm{OH})[\mathrm{BDC}] \cdot \mathrm{H}_{2} \mathrm{O}+3 \mathrm{H}_{2} \mathrm{O} \rightarrow \mathrm{Fe}_{2} \mathrm{O}_{3} \cdot 2 \mathrm{H}_{2} \mathrm{O}+2 \mathrm{H}_{2} \mathrm{BDC}
$$

To further explore this controversy, which would affect the potential application of MIL-53(Fe) as photocatalyst for the degradation of water pollutants, a series of MIL-53(Fe) stability experiments was carried out in water.

\subsubsection{Effect of Aqueous $\mathrm{pH}$}

First, the effect of $\mathrm{pH}$ on the stability of MIL-53(Fe) in water at $25^{\circ} \mathrm{C}$ was investigated. Figure 7 displays XRD results of samples after being soaked in different $\mathrm{pH}$ Milli-Q water for 20 days. Regardless of the initial $\mathrm{pH}$, the XRD patterns remained unchanged after exposure of MIL-53(Fe) to water, suggesting retained crystallinity. Additionally, no drastic changes were appreciated in FTIR results (not shown). However, a noticeable color change of the solid, from pale-orange to reddish-brown, was observed after the test carried out at initial pH 10 (Figure 7), which is a sign of the formation of hydrated iron species.

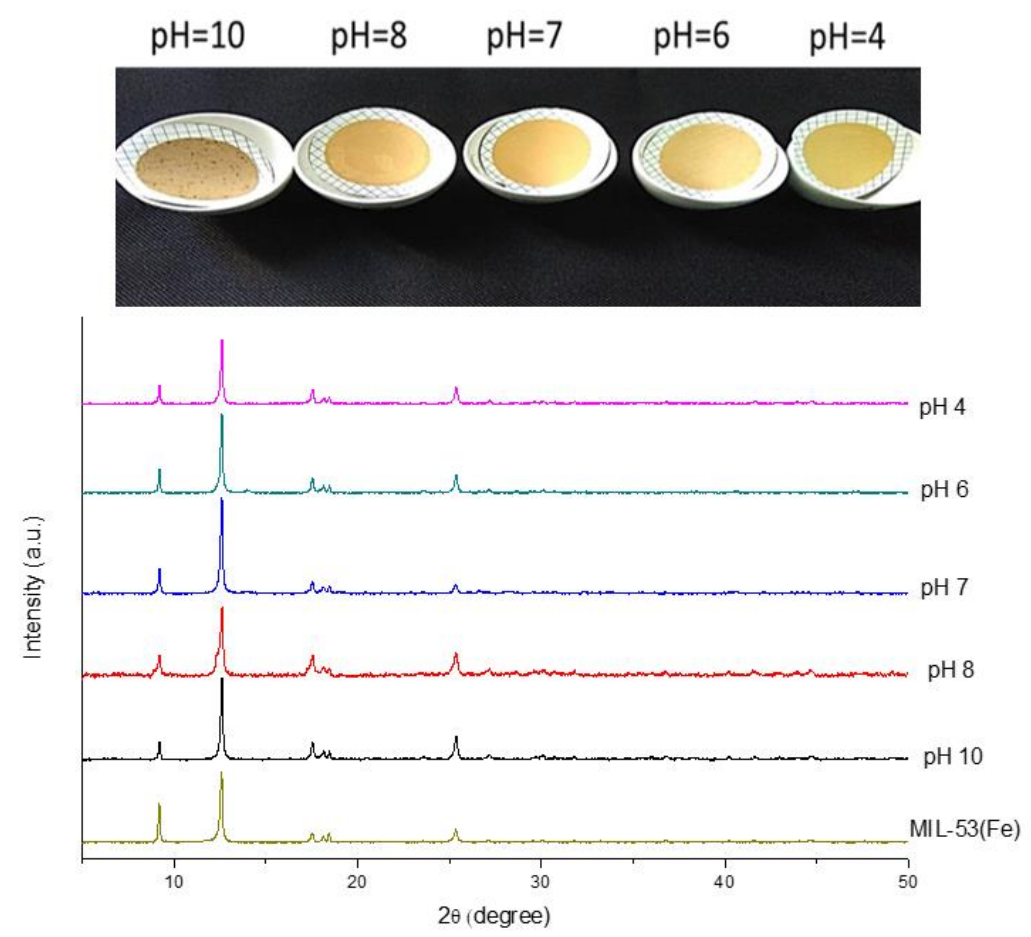

Figure 7. Effect of initial $\mathrm{pH}$ on the color transformation (up) and XRD patterns (down) of the synthesized MIL-53(Fe) before and after exposure to water at $25^{\circ} \mathrm{C}$ for 20 days.

Figure 8 shows the percentages of iron and carbon leached out from MIL-53(Fe) samples after prolonged contact with water. All dissolved organic carbon (DOC) found 
in solution in each experiment was due only to $\mathrm{H}_{2} \mathrm{BDC}$ molecules displaced from the solid, thus ruling out the formation of other carbonaceous products from the hydrolysis reaction. From Figure 8, it is apparent that MIL-53(Fe) stability decreased with initial pH, as the hydrolysis reaction of the MIL-53 structure was favored at alkaline conditions [57]. Thus, as much as $5 \%$ and $12 \%$ of iron and carbon, respectively, were leached out from the solid at $\mathrm{pH} 10$, resulting in 1.5 and $11.1 \mathrm{mg} \mathrm{L}^{-1}$ aqueous iron and DOC, respectively, whereas at $\mathrm{pH} 4$, little DOC (1.8 $\mathrm{mg} \mathrm{L}^{-1}$, i.e., $\left.3.1 \mathrm{mg} \mathrm{L}^{-1} \mathrm{H}_{2} \mathrm{BDC}\right)$ and negligible iron $\left(<0.15 \mathrm{mg} \mathrm{L}^{-1}\right)$ were found in solution. Nevertheless, it should be taken into account that iron in solution might underestimate the actual amount of this metal withdrawn from the MIL-53(Fe) structure since small particles of free iron oxides species (e.g., amorphous oxyhydroxides) resulting from partial hydrolysis of the framework could be deposited on the surface of MIL-53(Fe) [51]. The negative effect of the $\mathrm{pH}$ on the water stability of MIL-53(Fe) here found agrees with that recently reported for other iron-carboxylate MOF, namely, MIL-100(Fe) [53]. Accordingly, pH must be controlled in the acidic range to hinder the hydrolysis of iron-carboxylate frameworks to some extent.

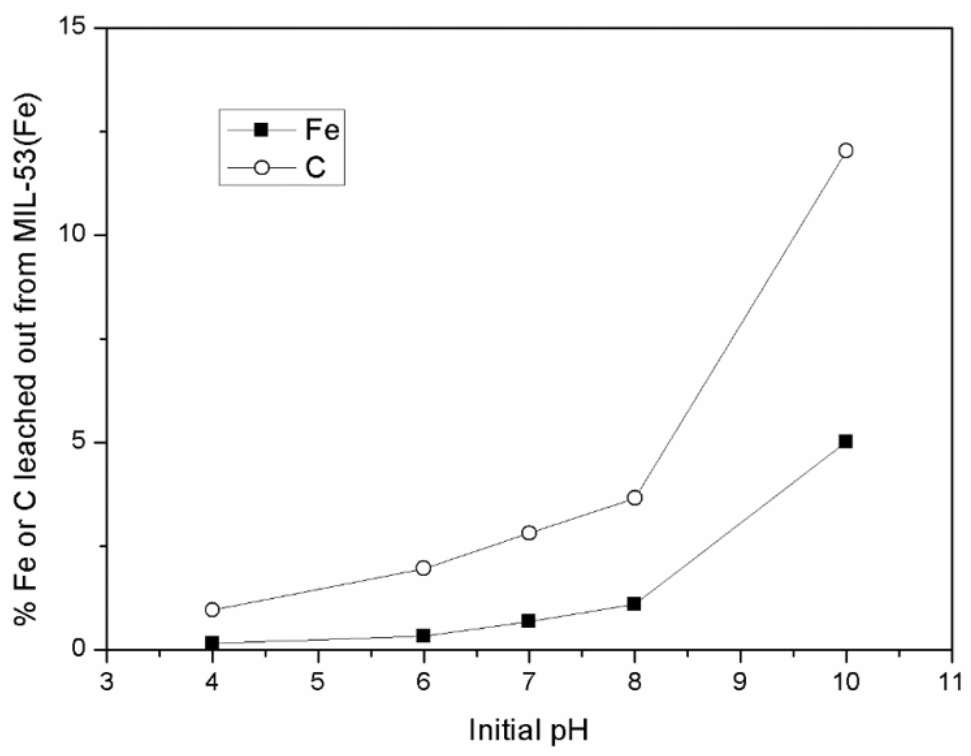

Figure 8. Effect of initial $\mathrm{pH}$ on the percentages of iron and carbon leached out from MIL-53(Fe) after exposure to water at $25^{\circ} \mathrm{C}$ for 20 days.

\subsubsection{Effect of UV-Vis Radiation and Temperature}

A series of experiments where MIL-53(Fe) samples were soaked in Milli-Q water at initial $\mathrm{pH} 4.5$ and constant temperature for $7 \mathrm{~h}$ was carried out to examine the impact of temperature $\left(25^{\circ} \mathrm{C}\right.$ and $\left.40^{\circ} \mathrm{C}\right)$ and radiation (solar and visible radiation) on the stability of MIL-53(Fe). Aqueous $\mathrm{pH}$ slightly decreased throughout all the tests in the 4.5-4.1 range. As shown in Figure 9, the amounts of iron and carbon leached out from MIL-53(Fe) were affected by both temperature and radiation. In the absence of radiation, temperature exerted a negative impact on MIL-53(Fe) stability likely because of increases in the rate of the hydrolysis reaction (1) and in $\mathrm{H}_{2} \mathrm{BDC}$ solubility. Both visible and simulated solar radiation also accelerated the leaching of carbon and iron from the framework structure, being the effect of solar radiation stronger. This suggests that the photogeneration of holes $\left(\mathrm{h}^{+}\right)$and ROS from MIL-53(Fe) activation under visible or solar radiation might contribute to decarboxylation of the MOF to some extent:

$$
\begin{gathered}
\text { MIL-53(Fe) }+\mathrm{h} v \rightarrow \text { MIL-53(Fe) }\left(\mathrm{e}^{-}, \mathrm{h}^{+}\right) \\
\mathrm{H}_{2} \mathrm{O}+\mathrm{h}^{+} \rightarrow \mathrm{HO}^{\bullet}+\mathrm{H}^{+} \\
\mathrm{O}_{2}+\mathrm{e}^{-} \rightarrow{ }^{\bullet} \mathrm{O}_{2}{ }^{-}
\end{gathered}
$$




$$
\begin{gathered}
2{ }^{\bullet} \mathrm{O}_{2}{ }^{-}+2 \mathrm{H}^{+} \rightarrow \mathrm{H}_{2} \mathrm{O}_{2}+\mathrm{O}_{2} \\
\mathrm{H}_{2} \mathrm{O}_{2}+\bullet \mathrm{O}_{2}{ }^{-} \rightarrow \mathrm{OH}^{-}+\mathrm{HO}^{\bullet}+\mathrm{O}_{2} \\
\mathrm{H}_{2} \mathrm{O}_{2}+\mathrm{e}^{-} \rightarrow \mathrm{OH}^{-}+\mathrm{HO}^{\bullet} \\
\mathrm{Fe}(\mathrm{OH})[\mathrm{BDC}] \cdot \mathrm{H}_{2} \mathrm{O}+\mathrm{h}^{+} /{ }^{\bullet} \mathrm{O}_{2}{ }^{-} / \mathrm{HO} \rightarrow \mathrm{H}_{2} \mathrm{BDC}+\text { Iron oxide species }
\end{gathered}
$$

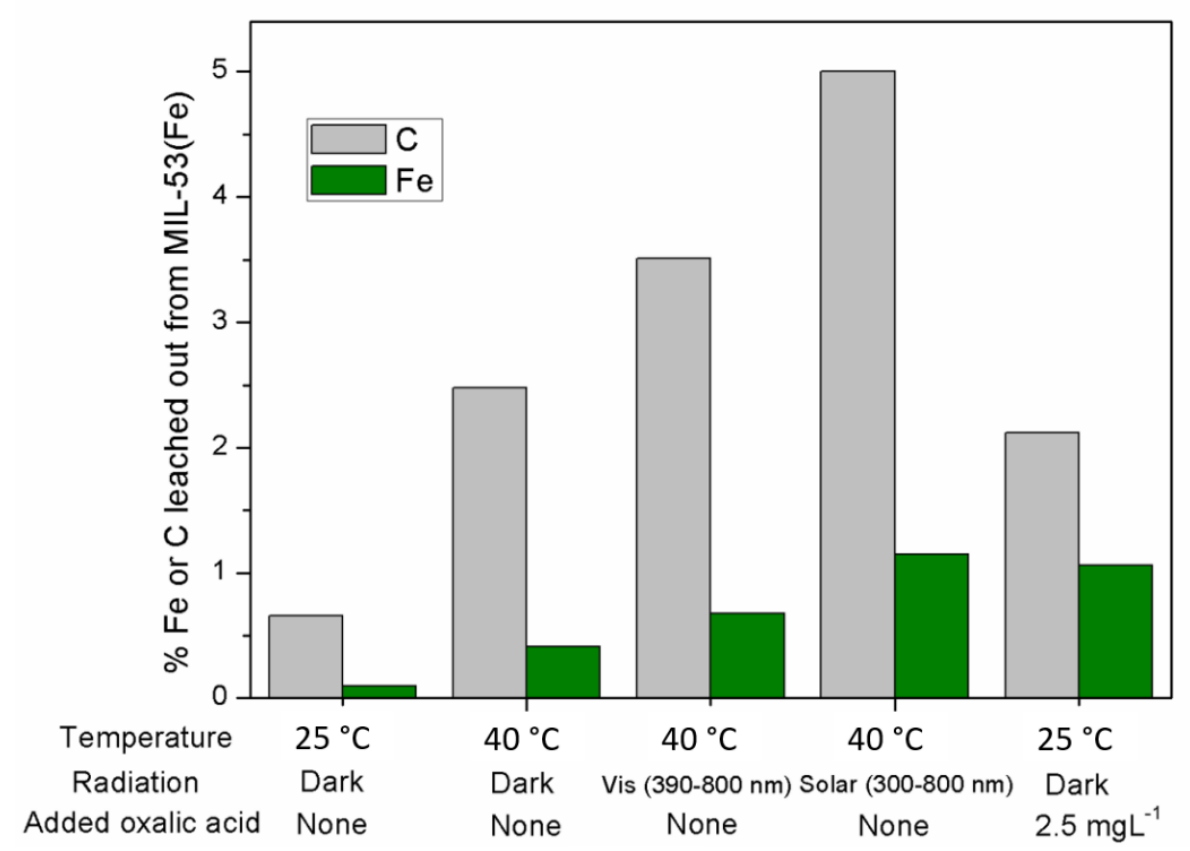

Figure 9. Effect of temperature and radiation on the percentage of iron and carbon leached out from MIL-53(Fe) after exposure to water for $7 \mathrm{~h}$.

Furthermore, photogenerated $\mathrm{HO}^{\bullet}$ would attack aqueous $\mathrm{H}_{2} \mathrm{BDC}$ to form intermediate products such as short-chain carboxylic acids (SCCAs) eventually yielding $\mathrm{CO}_{2}$ and $\mathrm{H}_{2} \mathrm{O}$ [52]:

$$
\mathrm{H}_{2} \mathrm{BDC}+\mathrm{HO}^{\bullet} \rightarrow \mathrm{H}_{2} \mathrm{BDC}-\mathrm{OH} \rightarrow \ldots \rightarrow \mathrm{SCCAs} \rightarrow \mathrm{CO}_{2}+\mathrm{H}_{2} \mathrm{O}
$$

It is interesting to note that in the runs carried out in the dark, all DOC belonged to aqueous $\mathrm{H}_{2} \mathrm{BDC}$, while in experiments in the presence of visible and simulated solar radiation, $\mathrm{H}_{2} \mathrm{BDC}$ in solution accounted just for $86.3 \%$ and $82.4 \%$ of overall DOC, respectively. Accordingly, accumulation of some $\mathrm{H}_{2} \mathrm{BDC}$ degradation products (e.g., SCCAs) took place to some extent only in irradiated runs, suggesting the formation of $\mathrm{HO}^{\bullet}$ upon MIL-53(Fe) illumination. It should be mentioned that the generated SCCAs might also contribute to iron leaching through organic complexation of $\mathrm{Fe}(\mathrm{III})$ (e.g., ferric-oxalate complexes) [58]. To investigate this effect, another MIL-53(Fe) stability run was conducted at $25^{\circ} \mathrm{C}$ in the dark adding oxalic acid $\left(2.5 \mathrm{mg} \mathrm{L}^{-1}\right)$ to the solution. Figure 9 reveals that the presence of oxalic acid three folded and ten folded the amounts of carbon and iron released from MIL-53(Fe) to water compared to the blank run. Moreover, the $\mathrm{H}_{2} \mathrm{BDC} / \mathrm{Fe}$ molar ratio found in solution after the run carried out with oxalic acid was 1.1 (close to the 1:1 MIL-53(Fe) stoichiometry) while in the absence of oxalic acid the ratio was as high as $6.7\left(25^{\circ} \mathrm{C}\right)$ and $6.0\left(40^{\circ} \mathrm{C}\right)$. This clearly suggests that in the presence of oxalic acid all iron extracted from MIL-53(Fe) was transferred to the aqueous phase as highly soluble ferric-oxalate complexes.

Despite the clear evidence of photo-decarboxylation of the BDC linker, XRD patterns and ATR-FTIR spectra peaks of an irradiated MIL-53(Fe) sample exhibited no apparent changes in the position and relative intensity respect to fresh MIL-53(Fe) as shown 
in Figure 10. In agreement with these results, other researchers have also found that decarboxylation of terephthalate-based MOFs is not frequently reflected in XRD and FTIR results [59].

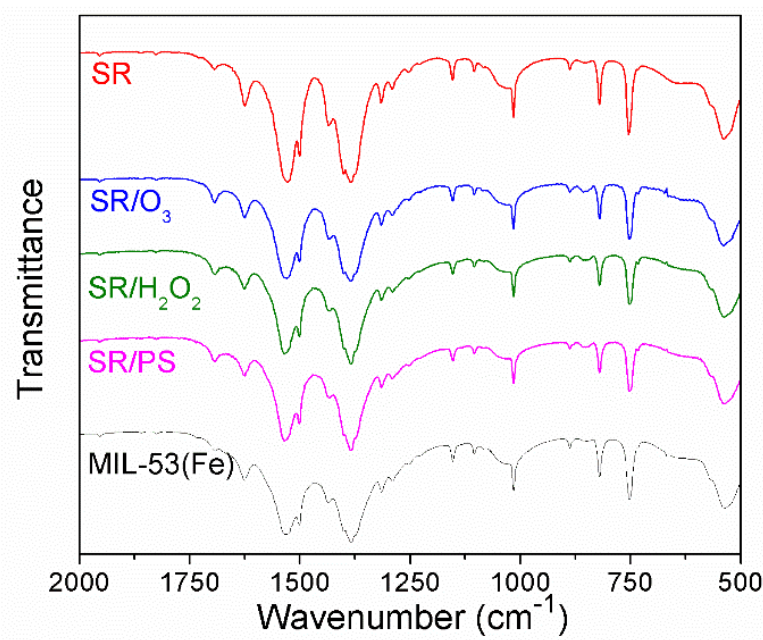

(a)

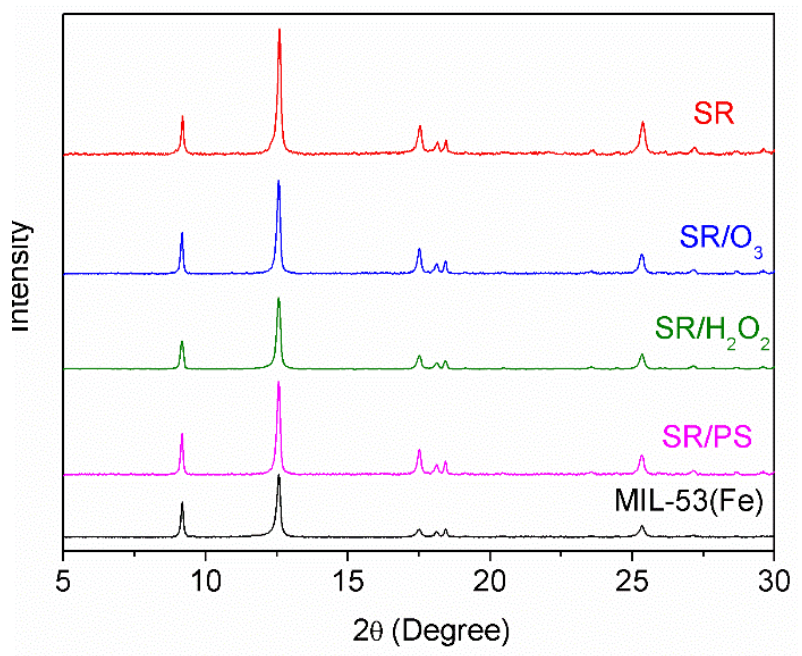

(b)

Figure 10. ATR-FTIR spectra (a) and XRD patterns (b) of MIL-53(Fe) after exposure to radiation and oxidants. MIL-53(Fe) treatment conditions: $\mathrm{SR}=$ Simulated solar radiation for $7 \mathrm{~h} ; \mathrm{SR} / \mathrm{O}_{3}=$ Simulated solar radiation/ozone $\left(1 \mathrm{mg} \mathrm{min}^{-1}\right)$ for $1 \mathrm{~h}$; $\mathrm{SR} / \mathrm{H}_{2} \mathrm{O}_{2}=$ Simulated solar radiation/hydrogen peroxide $(75 \mathrm{mM})$ for $1 \mathrm{~h}$; SR/PS = Simulated solar radiation/potassium persulfate $(2.5 \mathrm{mM})$ for $1 \mathrm{~h}$.

\subsubsection{Effect of Oxidants: Hydrogen Peroxide, Persulfate and Ozone}

The fast recombination of photogenerated electrons and holes in MIL-53(Fe) usually leads to unsatisfactory photocatalytic efficiency. To reduce this charge carrier recombination the use of some oxidants (i.e., electron acceptors), such as hydrogen peroxide or persulfate, has been frequently considered in research studies to enhance the photodegradation of water pollutants (see Table S1). However, the oxidation power of these species and the enhanced generation of ROS might compromise MIL-53(Fe) stability. Figure 11 shows the evolution of the concentrations of aqueous iron, $\mathrm{H}_{2}$ BDC and SCCAs during MIL-53(Fe) photostability tests performed at $40^{\circ} \mathrm{C}$ and $\mathrm{pH}=4.0-4.5$ under simulated solar radiation in the presence of hydrogen peroxide, persulfate (PS) or ozone. Results clearly demonstrate that all the tested oxidants accelerated the leaching of iron and $\mathrm{H}_{2} \mathrm{BDC}$ out of MIL-53(Fe). In the absence of added oxidant, solar radiation provoked a steadily release of both linker and metal with a constant $\mathrm{H}_{2} \mathrm{BDC} / \mathrm{Fe}$ molar ratio of about 4 and negligible formation of SCCAs as oxidation products. However, the incorporation of electron acceptors (i.e., $\mathrm{H}_{2} \mathrm{O}_{2}$, $\mathrm{PS}$ or $\mathrm{O}_{3}$ ) to the photocatalytic process led to an increased generation of ROS, particularly $\mathrm{HO}^{\bullet}$ and, as a consequence, partial removal of the released linker. Accordingly, $\mathrm{H}_{2} \mathrm{BDC}$ concentration profiles in Figure 11 show a peak concentration at the beginning of the experiments followed by a continuous decline likely due to $\mathrm{HO}^{\bullet}$ attack to $\mathrm{H}_{2} \mathrm{BDC}$, which is a known probe for photochemically generated hydroxyl radicals [52]. In addition to reactions (2) to (7), the production of ROS in MIL-53(Fe) photocatalytic processes aided by oxidants can be explained by the following sets of reactions: 


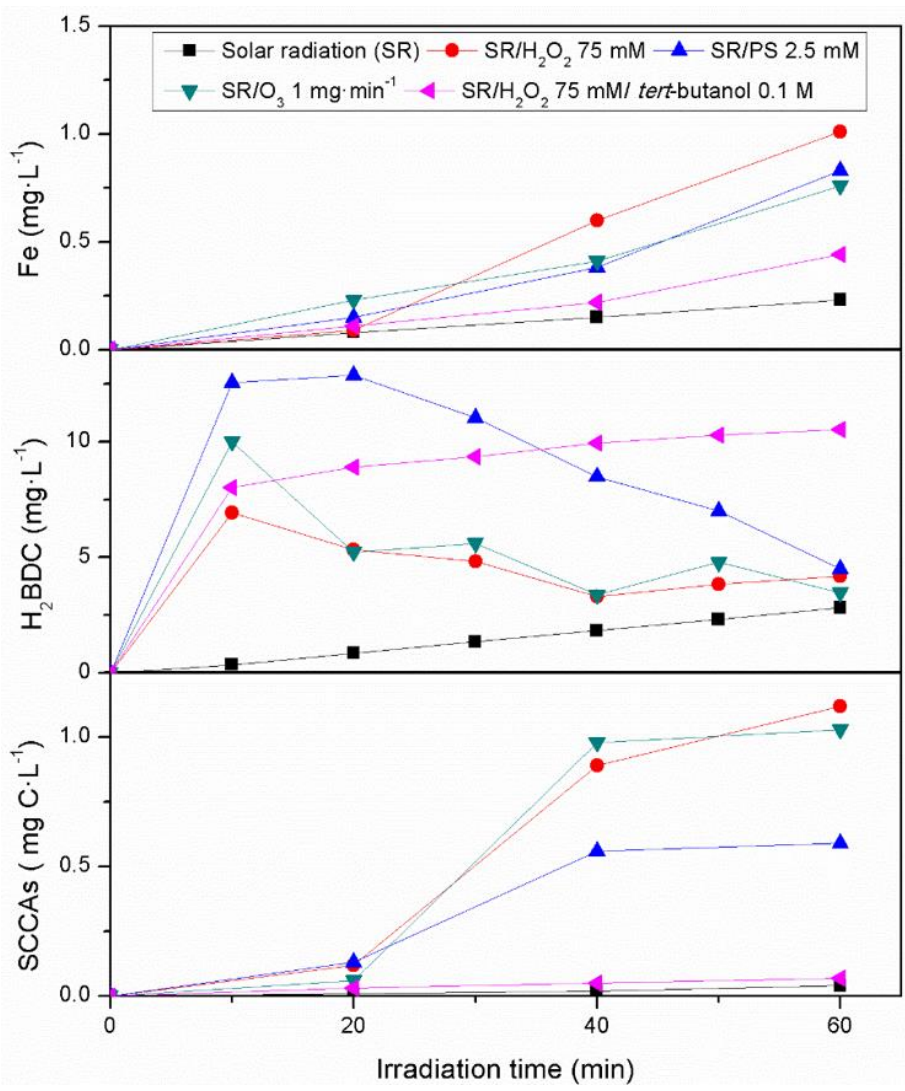

Figure 11. Effect of oxidants on the photostability of MIL-53(Fe) in water. Nomenclature of runs as in Figure 10.

Hydrogen peroxide [16]:

$$
\begin{gathered}
\text { MIL-53 }\left(\mathrm{Fe}^{3+}\right)+\mathrm{H}_{2} \mathrm{O}_{2} \rightarrow \text { MIL-53 }\left(\mathrm{Fe}^{2+}\right)+\mathrm{H}^{+}+\mathrm{HO}_{2}^{\bullet} \\
\text { MIL-53( } \left.\mathrm{Fe}^{2+}\right)+\mathrm{H}_{2} \mathrm{O}_{2} \rightarrow \text { MIL-53 }\left(\mathrm{Fe}^{3+}\right)+\mathrm{OH}^{-}+\mathrm{HO}^{\bullet} \\
\mathrm{HO}_{2}{ }^{\bullet}+\mathrm{OH}^{-} \rightarrow \mathrm{O}_{2}{ }^{-}+\mathrm{H}_{2} \mathrm{O}
\end{gathered}
$$

Persulfate [42]:

$$
\begin{gathered}
\text { MIL-53 }\left(\mathrm{Fe}^{3+}\right)+\mathrm{S}_{2} \mathrm{O}_{8}{ }^{2-} \rightarrow \mathrm{MIL}-53\left(\mathrm{Fe}^{2+}\right)+\mathrm{S}_{2} \mathrm{O}_{8}{ }^{-\bullet} \\
\text { MIL-53( } \left.\mathrm{Fe}^{2+}\right)+\mathrm{S}_{2} \mathrm{O}_{8}{ }^{2-} \rightarrow \text { MIL-53 }\left(\mathrm{Fe}^{2+}\right)+\mathrm{SO}_{4}{ }^{-\bullet}+\mathrm{SO}_{4}{ }^{2-} \\
\mathrm{S}_{2} \mathrm{O}_{8}{ }^{2-}+\mathrm{e}^{-} \rightarrow \mathrm{SO}_{4}{ }^{-\bullet}+\mathrm{SO}_{4}{ }^{2-} \\
\mathrm{SO}_{4}{ }^{-\bullet}+\mathrm{H}_{2} \mathrm{O} \rightarrow \mathrm{SO}_{4}{ }^{2-}+\mathrm{HO}^{\bullet}+\mathrm{H}^{+} \\
\mathrm{S}_{2} \mathrm{O}_{8}{ }^{2-}+\mathrm{hv} \rightarrow 2 \mathrm{SO}_{4}{ }^{-}
\end{gathered}
$$

Ozone [53,60]:

$$
\begin{gathered}
\text { MIL-53 }\left(\mathrm{Fe}^{3+}\right)+\mathrm{O}_{3}+\mathrm{OH}^{-} \rightarrow \mathrm{MIL}-53\left(\mathrm{Fe}^{2+}\right)+\mathrm{HO}_{2}{ }^{\bullet}+{ }^{1} \mathrm{O}_{2} \\
\text { MIL-53 }\left(\mathrm{Fe}^{2+}\right)+\mathrm{O}_{3}+\mathrm{H}_{2} \mathrm{O} \rightarrow \text { MIL-53 }\left(\mathrm{Fe}^{3+}\right)+\mathrm{OH}^{-}+\mathrm{HO}^{\bullet}+\mathrm{O}_{2} \\
\mathrm{O}_{3}+\mathrm{e}^{-}+\mathrm{H}_{2} \mathrm{O} \rightarrow{ }^{1} \mathrm{O}_{2}+{ }^{\bullet} \mathrm{O}_{2}{ }^{-}+\mathrm{HO}^{\bullet} \\
\mathrm{O}_{3}+\mathrm{H}_{2} \mathrm{O}+\mathrm{hv} \rightarrow{ }^{1} \mathrm{O}_{2}+\mathrm{H}_{2} \mathrm{O}_{2}
\end{gathered}
$$

The degradation of aqueous $\mathrm{H}_{2} \mathrm{BDC}$ by $\mathrm{ROS}$ resulted in the accumulation of SCCAs in solution as shown in Figure 11. This is in agreement with previous studies where some 
SCCAs such as muconic acid, fumaric acid, maleic acid or oxalic acid were identified as products of advanced oxidation of aqueous $\mathrm{H}_{2} \mathrm{BDC}[61,62]$. The generated SCCAs might also contribute to prevent iron precipitation and to enhance the production of ROS through organic complexation of Fe(III) (e.g., ferric-oxalate complexes). Under UV-vis radiation, $\mathrm{Fe}(\mathrm{III})$-carboxylate complexes can undergo photolysis with formation of $\mathrm{HO}^{\bullet}$ and the pair $\mathrm{HO}_{2}{ }^{\bullet} / \mathrm{O}_{2}{ }^{-}$[63], activate PS decomposition into $\mathrm{SO}_{4}{ }^{-\bullet}$ and $\mathrm{HO}^{\bullet}$ [64] or improve the $\mathrm{HO}$ yield in photo-Fenton-like and photo-ozonation processes [65,66]. Moreover, as discussed above, some SCCAs (e.g., oxalate) have the ability to extract iron from solids through complex formation. In line with this, Figure 11 shows that dissolved iron concentration in runs carried out in the presence of oxidants increased specially after $20 \mathrm{~min}$ when the concentration of SCCAs started to be significant.

To further investigate the effect of photogenerated $\mathrm{HO}^{\bullet}$ on MIL-53(Fe) stability, a test was run under solar radiation with added $\mathrm{H}_{2} \mathrm{O}_{2}(75 \mathrm{mM})$ and tert-butanol $(100 \mathrm{mM})$, a powerful $\mathrm{HO}^{\bullet}$ scavenger. As it can be seen in Figure 11, the quenching of $\mathrm{HO}^{\bullet}$ by tertbutanol drastically decreased the amount of iron released from MIL-53(Fe) to the aqueous medium compared to the parallel experiment carried out with $\mathrm{H}_{2} \mathrm{O}_{2}$ but in the absence of tert-butanol. Moreover, because of the $\mathrm{HO}^{\bullet}$ scavenging effect of tert-butanol a steadily accumulation of $\mathrm{H}_{2} \mathrm{BDC}$ and practically no formation of SCCAs were observed along the experiment. These findings suggest that photogenerated $\mathrm{HO}^{\bullet}$ might attack iron nodes of MIL-53(Fe) leading to the release of both iron and linker to solution.

Samples of MIL-53(Fe) were examined by XRD and ATR-FTIR after being exposed to solar radiation and $\mathrm{H}_{2} \mathrm{O}_{2}, \mathrm{PS}$ or $\mathrm{O}_{3}$ for $1 \mathrm{~h}$. The results displayed in Figure 10 show no appreciable changes in XRD patterns and ATR-FTIR spectra compared to those of fresh MIL-53(Fe). Therefore, the observed instability of MIL-53(Fe) under oxidizing environment evidenced in Figure 11 is not appreciated in XRD and ATR-FTIR results.

\subsection{Photocatalytic Activity of MIL-53(Fe) under Simulated Solar Radiation}

The photocatalytic performance of the as-prepared MIL-53(Fe) was evaluated by the removal of aqueous $\mathrm{Ph}$ and MTP. Hydrogen peroxide, persulfate and ozone were used in some experiments to accelerate the degradation process. Figure 12 shows the removal of both target pollutants during $3 \mathrm{~h}$ of exposure to simulated solar radiation. Before irradiation, an initial dark stage was considered in the absence of simulated solar radiation and oxidant to allow for Ph or MTP adsorption onto MIL-53(Fe). However, as little as $1.1 \mathrm{mg} \mathrm{Ph} / \mathrm{g}$ MIL-53(Fe) and $2.1 \mathrm{mg}$ MTP/g MIL-53(Fe) (average values) were adsorbed onto MIL-53(Fe) after the 30-min dark stage. Moreover, the synthetized MIL53(Fe) demonstrated low photocatalytic activity towards the degradation of Ph and MTP under simulated solar radiation in the absence of added oxidants with only $8.5 \% \mathrm{Ph}$ removal and 9.5\% MTP removal after $3 \mathrm{~h}$ of irradiation. This low photodegradation rate can be ascribed to a fast electron-hole recombination [15]. The addition of any oxidant greatly enhanced the photodegradation rate leading to complete removal of Ph and MTP in less than $2 \mathrm{~h}$. The added oxidants $\left(\mathrm{H}_{2} \mathrm{O}_{2}\right.$, $\mathrm{PS}$ or $\left.\mathrm{O}_{3}\right)$ might play several roles leading to the acceleration of Ph and MTP removal rates: (i) direct attack of the oxidant to the target pollutants; (ii) MIL-53(Fe) mediated catalytic degradation of pollutants (non-photocatalytic routes); (iii) enhancement of photocatalytic degradation routes.

In Figure 13 it can be appreciated that neither simulated solar radiation nor MIL-53(Fe) had any improving effect on the removal rate of Ph and MTP by ozonation. Taking into account the high rate constants between molecular ozone and both organic compounds at the working $\mathrm{pH}$ (i.e., $1.3 \mathrm{mM}^{-1} \mathrm{~s}^{-1}$ and $1.4 \mathrm{mM}^{-1} \mathrm{~s}^{-1}$ for Ph and MTP, respectively $[67,68]$ ), the results of Figure 13 clearly suggest that both contaminants were primarily removed by direct ozonation. Moreover, no ozone was found in solution during the first $60 \mathrm{~min}$ of reaction indicating that a fast kinetic regime of ozone absorption developed in this period. Accordingly, reactions would take place in the liquid film close to the gas-liquid interface regardless of the irradiation or the use of MIL-53(Fe) as photocatatlyst. At reaction time longer than ca. $1 \mathrm{~h}$, when fast-reacting ozone compounds were eliminated, ozone started 
to accumulate in solution. Then, ROS formation from ozone reactions in water (18) to (21) would develop. Accordingly, both solar radiation and MIL-53(Fe) would favor the generation of ROS involved in the degradation mechanism [14,62]. As a result, irradiation enhanced DOC removal, as can be observed in Figure 13, and low concentration of SCCAs was found in the treated water (not shown). However, Figure 13 evidences poorer results in terms of DOC removal for the MIL-53(Fe)/SR/O $\mathrm{O}_{3}$ system than for the $\mathrm{SR} / \mathrm{O}_{3}$. The negative effect of MIL-53(Fe) can be ascribed to the decarboxylation of the MOF in the presence of ozone as discussed in Section 2.2.3. The leaching of $\mathrm{H}_{2} \mathrm{BDC}$ ligand molecules out of the solid led to an increased content of organic matter in solution, which competed with Ph or MTP degradation products for ROS.

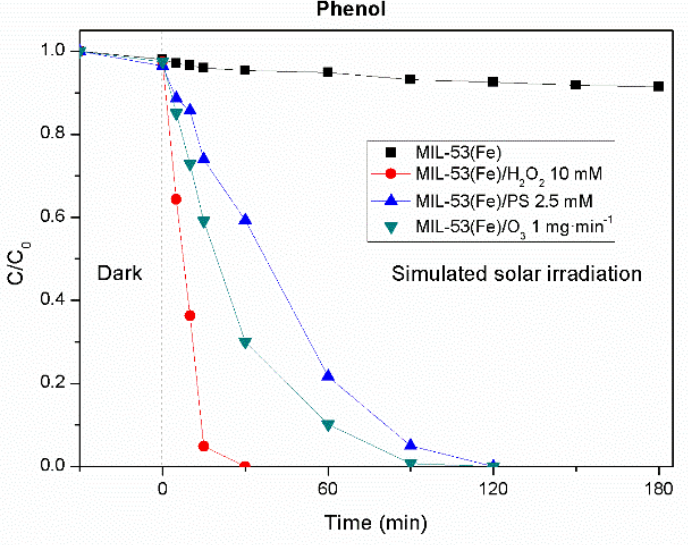

(a)

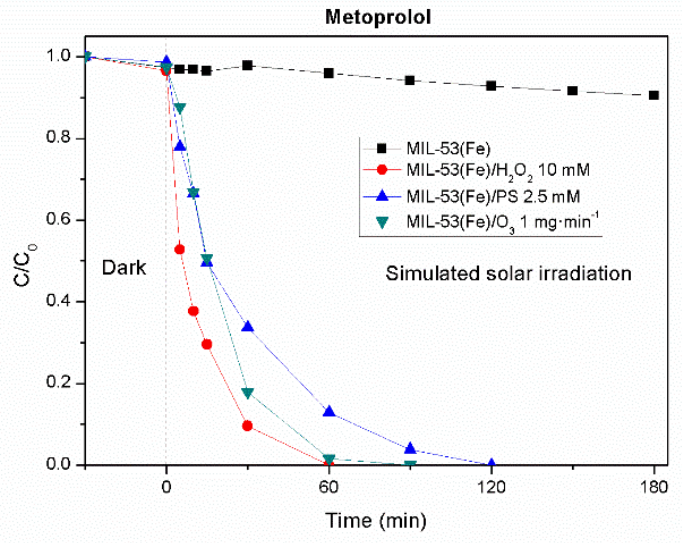

(b)

Figure 12. Photodegradation of phenol (Ph) (a) and metoprolol (MTP) (b) under simulated solar radiation in different MIL-53(Fe) catalytic systems. Experimental conditions: MIL-53(Fe) concentration $=0.6 \mathrm{~g} \mathrm{~L}^{-1}$; Pollutant initial concentration: $\mathrm{Ph} 25 \mathrm{mg} \mathrm{L}^{-1}$, MTP $50 \mathrm{mg} \mathrm{L}^{-1} ; \mathrm{pH}=4-5$.

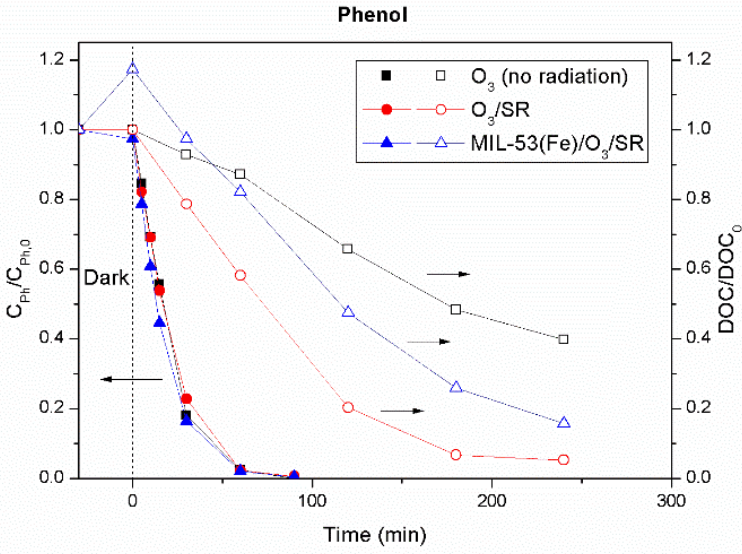

(a)

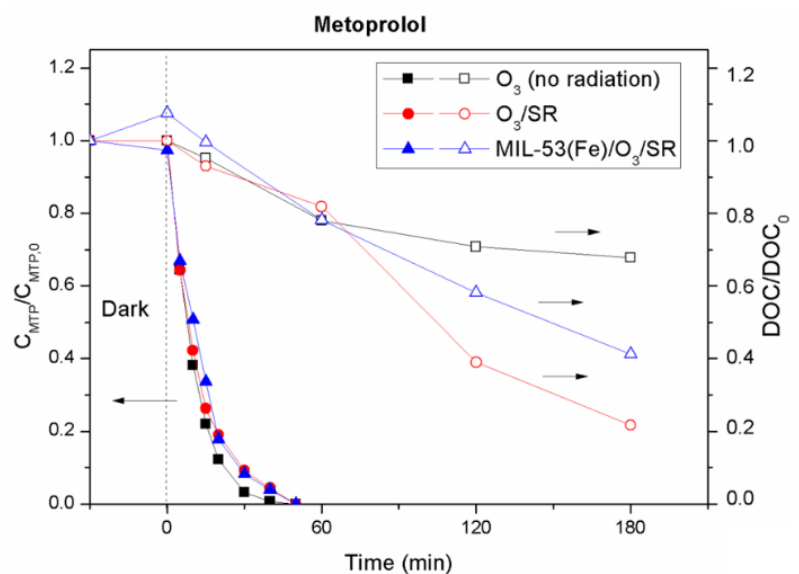

(b)

Figure 13. Effect of simulated solar radiation and MIL-53(Fe) on the ozonation of aqueous phenol ( $\mathrm{Ph})(\mathbf{a})$ and metoprolol $(\mathrm{MTP})(\mathrm{b})$. Experimental conditions: MIL-53(Fe) concentration (if used) $=0.6 \mathrm{~g} \mathrm{~L}^{-1}$; Pollutant initial concentration: Ph $25 \mathrm{mg} \mathrm{L}^{-1}$, MTP $50 \mathrm{mg} \mathrm{L}^{-1}$; $\mathrm{pH}=4-5$; Ozone mass flowrate: $1 \mathrm{mg} \mathrm{min}^{-1}$.

Figure 14 reveals that PS on its own (PS/dark) could not remove Ph or MTP to any extent. However, simulated solar light activated PS leading to almost complete disappearance of Ph and MTP after $3 \mathrm{~h}$ of irradiation. At the working $\mathrm{pH}(4-5), \mathrm{SO}_{4}{ }^{-}$is believed to be the major contributing radical responsible for the destruction of the organic contaminants in the PS/SR system [69]. Accordingly, both Ph and MTP, with comparable $\mathrm{SO}_{4}{ }^{-\bullet}$ 
rate constant values $\left(\mathrm{k}_{\mathrm{Ph}}=8.8 \times 10^{10} \mathrm{M}^{-1} \mathrm{~s}^{-1}[70]\right.$ and $\left.\mathrm{k}_{\mathrm{MTP}}=1.0 \times 10^{10} \mathrm{M}^{-1} \mathrm{~s}^{-1}[71]\right)$, showed similar removal profiles. When MIL-53(Fe) was used in combination with simulated solar radiation and PS, better photocatalytic performance in terms of Ph and MTP removal rates was obtained as illustrated in Figure 14. MIL-53(Fe) is reported to directly activate PS leading to $\mathrm{SO}_{4}{ }^{-\bullet}, \boldsymbol{O}_{2}{ }^{-}$and $\mathrm{HO}^{\bullet}$ in aqueous acidic media [13]. However, PS activation could also be induced by Fe(III) species leached out from MIL-53(Fe) such as iron oxhydroxides and dissolved $\mathrm{Fe}^{3+}$ [72]. Furthermore, electron-hole recombination is avoided to some extent through reaction (15) [24,35]. As a consequence, the formation of ROS with the MIL-53(Fe)/PS/RS combination was favored compared to MIL-53(Fe)/SR, MIL-53(Fe)/PS or PS/SR systems.

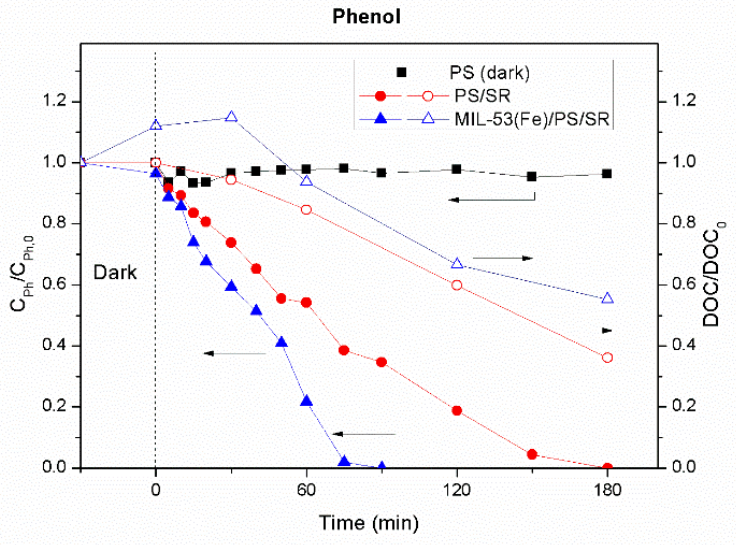

(a)

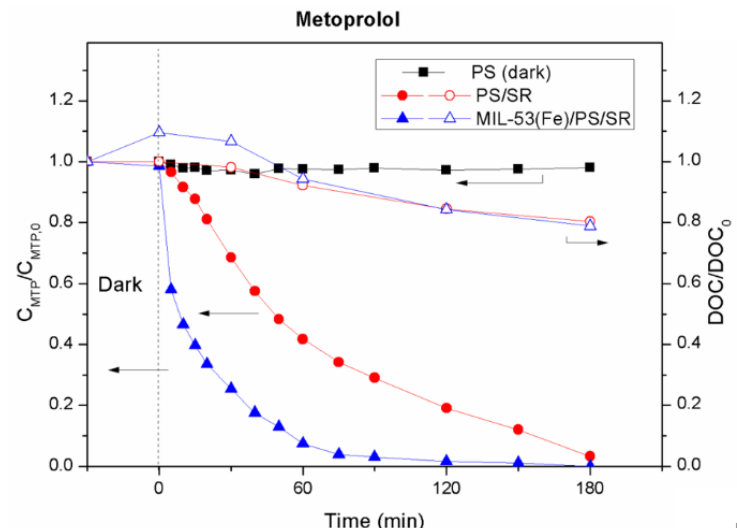

(b)

Figure 14. Effect of simulated solar radiation and MIL-53(Fe) on the oxidation of aqueous phenol (Ph) (a) and metoprolol (MTP) (b) by PS. Experimental conditions: MIL-53(Fe) concentration (if used) $=0.6 \mathrm{~g} \mathrm{~L}^{-1}$; Pollutant initial concentration: Ph $25 \mathrm{mg} \mathrm{L}^{-1}$, MTP $50 \mathrm{mg} \mathrm{L}^{-1}$; $\mathrm{pH}=4-5$; PS initial concentration= $2.5 \mathrm{mM}$.

The effect of $\mathrm{H}_{2} \mathrm{O}_{2}$ on the degradation of Ph and MTP is illustrated in Figure 15. It is clearly seen that the $\mathrm{H}_{2} \mathrm{O}_{2} / \mathrm{SR}$ system barely eliminated $10 \%$ of the target pollutants in $3 \mathrm{~h}$ of reaction despite the fact that hydrogen peroxide may undergo photolytic breakdown into ROS under illumination by solar radiation [60]. However, the MIL-53(Fe) $/ \mathrm{H}_{2} \mathrm{O}_{2}$ processes both in the dark and under simulated solar radiation led to complete removal of the pollutants in less than $2 \mathrm{~h}$ and $1 \mathrm{~h}$, respectively.

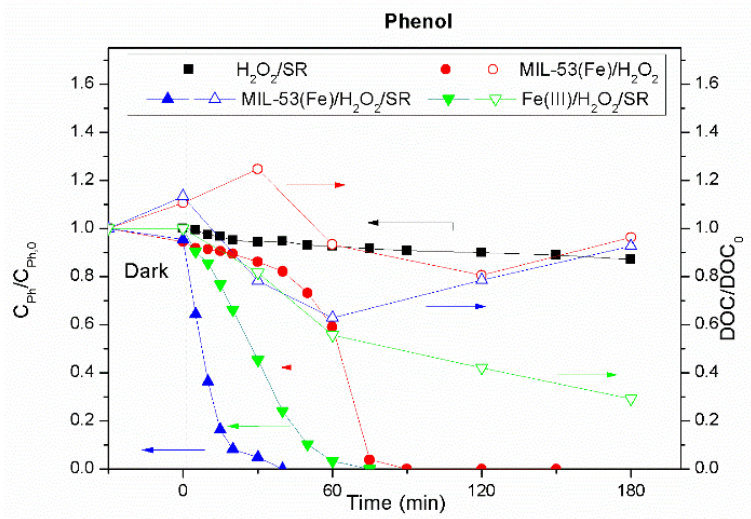

(a)

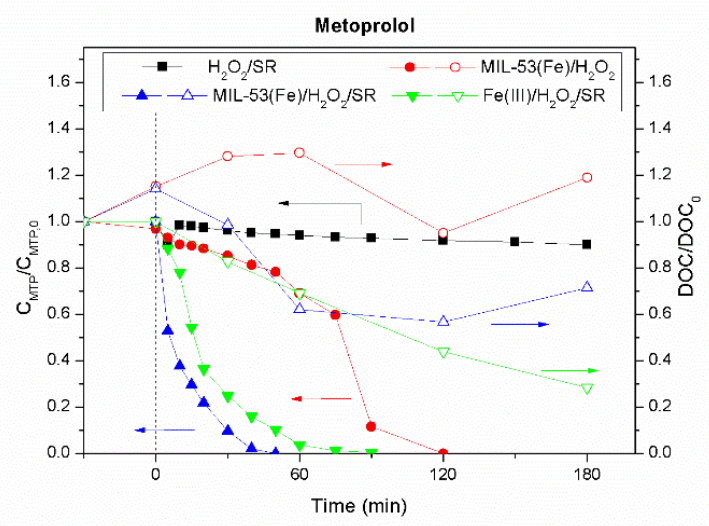

(b)

Figure 15. Degradation of aqueous phenol (Ph) (a) and metoprolol (MTP) (b) by $\mathrm{H}_{2} \mathrm{O}_{2}$ assisted catalytic and photocatalytic processes. Experimental conditions: MIL-53(Fe) concentration (if used) $=0.6 \mathrm{~g} \mathrm{~L}^{-1}$; Pollutnat initial concentration: $\mathrm{Ph}$ $25 \mathrm{mg} \mathrm{L}^{-1}$, MTP $50 \mathrm{mg} \mathrm{L}^{-1} ; \mathrm{pH}=4-5 ; \mathrm{H}_{2} \mathrm{O}_{2}$ initial concentration: $10 \mathrm{mM}$; Fe(III) initial concentration (if used): $0.5 \mathrm{mg} \mathrm{L}{ }^{-1}$. 
It is interesting to note in Figure 15 that the shape of any pollutant decay profile differs significantly between Fenton-like (MIL-53(Fe) $/ \mathrm{H}_{2} \mathrm{O}_{2}$ ) and photo-Fenton like (MIL$\left.53(\mathrm{Fe}) / \mathrm{H}_{2} \mathrm{O}_{2} / \mathrm{SR}\right)$ experiments. Such difference is also reflected in the $\mathrm{H}_{2} \mathrm{O}_{2}$ concentration profiles shown in Figure 16. The inverted S-shaped curve observed in MIL-53(Fe) $/ \mathrm{H}_{2} \mathrm{O}_{2}$ runs carried in the dark suggests that the role of MIL-53(Fe) as a heterogeneous Fenton-like catalysts was not significant (i.e., reactions (10) and (11) would be rather slow). Accordingly, minor pollutant removal and $\mathrm{H}_{2} \mathrm{O}_{2}$ consumption were observed within the first $30 \mathrm{~min}$ of reaction when the concentration of iron in solution was still low $\left(<0.5 \mathrm{mg} \mathrm{L}^{-1}\right)$ (see Figure 16). As the run progressed, increasing amounts of iron leached out from MIL-53(Fe) into solution, thus favoring the homogeneous Fenton-like reactions [73]:

$$
\begin{aligned}
\mathrm{Fe}^{3+}+\mathrm{H}_{2} \mathrm{O}_{2} & \rightarrow \mathrm{Fe}^{2+}+\mathrm{HO}_{2}^{\bullet}+\mathrm{H}^{+} \quad\left(\mathrm{k}_{22}=10^{-2} \mathrm{M}^{-1} \mathrm{~s}^{-1}\right) \\
\mathrm{Fe}^{2+}+\mathrm{H}_{2} \mathrm{O}_{2} & \rightarrow \mathrm{Fe}^{3+}+\mathrm{OH}^{-}+\mathrm{HO}^{\bullet} \quad\left(\mathrm{k}_{23}=76 \mathrm{M}^{-1} \mathrm{~s}^{-1}\right) \\
\mathrm{Fe}^{2+}+\mathrm{HO}^{\bullet} & \rightarrow \mathrm{Fe}^{2+}+\mathrm{OH}^{-} \quad\left(\mathrm{k}_{24}=4.3 \times 10^{8} \mathrm{M}^{-1} \mathrm{~s}^{-1}\right)
\end{aligned}
$$

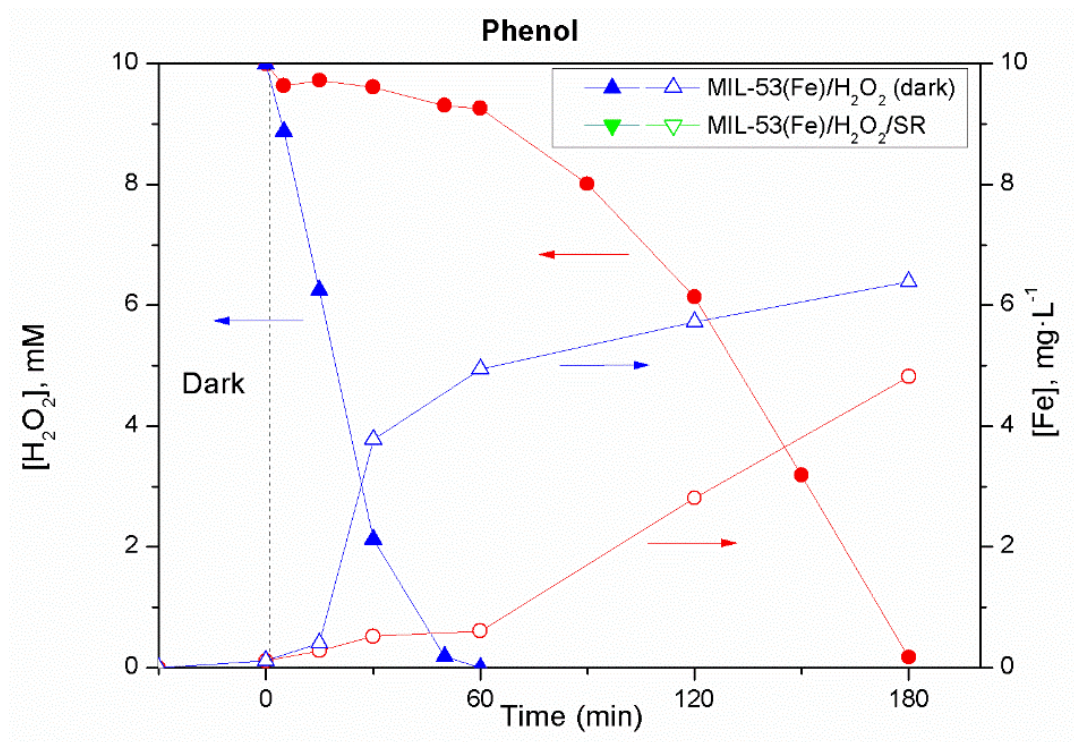

Figure 16. Hydrogen peroxide and iron concentration profiles during the degradation of phenol by $\mathrm{H}_{2} \mathrm{O}_{2}$ assisted catalytic and photocatalytic processes using MIL-53(Fe). Experimental conditions: MIL-53(Fe) concentration $=0.6 \mathrm{~g} \mathrm{~L}^{-1}$; Pollutant initial concentration: $\mathrm{Ph} 25 \mathrm{mg} \mathrm{L}{ }^{-1}$, $\mathrm{pH}=4-5 ; \mathrm{H}_{2} \mathrm{O}_{2}$ initial concentration: $10 \mathrm{mM}$.

Furthermore, partial oxidation of the parent compound (i.e., Ph or MTP) by generated ROS (i.e., $\mathrm{HO}^{\bullet}$ and $\mathrm{HO}_{2}{ }^{\bullet}$ ) would produce some intermediate products (e.g., hydroquinone and quinone-type products) acting as reducing agents $\left(\mathrm{Fe}^{3+} \rightarrow \mathrm{Fe}^{2+}\right)$ or electron-transfer catalysts, making the process auto-catalytic [73]. Some authors have reported enhanced Fenton-like catalysis by MIL-53(Fe) for the degradation of phenol [9-11]. However, in line with our results, from their conversion-time plots it is inferred that phenol was hardly degraded within the first 30 min of the MIL- $53(\mathrm{Fe}) / \mathrm{H}_{2} \mathrm{O}_{2}$ oxidation experiments when dissolved iron concentration was found below $0.6 \mathrm{mg} \cdot \mathrm{L}^{-1}$ [11]. The relatively low number of coordinatively unsaturated iron sites in MIL-53(Fe) could explain such limited catalytic activity. On the other hand, apparent first-order kinetics without lag phase is observed in Figure 15 for both Ph $\left(k_{\mathrm{obs}}=0.107 \mathrm{~min}^{-1}, \mathrm{R}^{2}=0.970\right)$ and MTP $\left(\mathrm{k}_{\mathrm{obs}}=0.089 \mathrm{~min}^{-1}\right.$, $\left.\mathrm{R}^{2}=0.966\right)$ removals in the MIL-53(Fe) photo-assisted runs, which agrees with previous studies on the photodegradation of water pollutants by MIL-53(Fe) $/ \mathrm{H}_{2} \mathrm{O}_{2}$ under UVvisible or visible light irradiation [15-17,20,23,33,40]. The absence of lag phase in pollutant conversion and fast decomposition of $\mathrm{H}_{2} \mathrm{O}_{2}$ from the beginning of MIL-53(Fe) $/ \mathrm{H}_{2} \mathrm{O}_{2} / \mathrm{SR}$ experiments when the dissolved iron concentration was small (see Figure 16) are signs of 
some heterogeneous photocatalytic ability of MIL-53(Fe) for the degradation of $\mathrm{Ph}$ and MTP through $\mathrm{H}_{2} \mathrm{O}_{2}$ mediated reactions.

In addition to the role of MIL-53(Fe) as heterogeneous catalyst to activate $\mathrm{H}_{2} \mathrm{O}_{2}$ under sunlight, its instability under the reaction conditions and the resulting release of iron and $\mathrm{H}_{2} \mathrm{BDC}$ into solution might have an impact on the pollutant degradation. On the one hand, aqueous iron could significantly contribute to ROS generation via homogeneous photo-Fenton-like mechanism initiated by photogeneration of Fe(II):

$$
\left[\mathrm{Fe}^{\mathrm{III}}\left(\mathrm{H}_{2} \mathrm{O}\right)\right]^{3+}+\mathrm{h} \cdot \mathrm{v} \rightarrow \mathrm{Fe}^{2+}+\mathrm{HO}^{\bullet}+\mathrm{H}^{+}
$$

Some SCCAs (e.g., oxalic acid) are typically viewed as intermediates of organic molecules oxidation by ROS (e.g., see as an example reference [74] for Ph degradation). In the MIL-53(Fe) $/ \mathrm{H}_{2} \mathrm{O}_{2} /$ SR experiments conducted in this work, concentrations of SCCAs as high as 8.4 and $5.1 \mathrm{mg} \mathrm{C} \mathrm{L}^{-1}$ were measured during the degradation of Ph and MTP, respectively. In the absence of radiation (i.e., MIL-53(Fe) $/ \mathrm{H}_{2} \mathrm{O}_{2}$ experiments) the accumulation of SCCAs was much lower with peak concentrations at longer reaction times. As discussed before, some SCCAs have the ability of both extracting iron from solid species and forming iron complexes with photochemical activity under UV-vis radiation leading to ROS generation [58,63]:

$$
\begin{aligned}
{\left[\mathrm{Fe}^{\mathrm{III}} \mathrm{RCOO}\right]^{2+}+\mathrm{h} \cdot \mathrm{v} } & \rightarrow \mathrm{Fe}^{2+}+\mathrm{CO}_{2}+\mathrm{R}^{\bullet} \\
\mathrm{R}^{\bullet}+\mathrm{O}_{2} & \rightarrow \mathrm{ROS}
\end{aligned}
$$

As an example, Figure 16 shows a dramatic increase of iron in solution beginning at 15 min of irradiation time in a MIL-53( $\mathrm{Fe}) / \mathrm{H}_{2} \mathrm{O}_{2} / \mathrm{SR}$ run treating aqueous phenol. The maximum concentration of SCCAs, particularly oxalic acid $\left(10.1 \mathrm{mg} \mathrm{L}^{-1}\right)$, was detected at $30 \mathrm{~min}$ irradiation time. Therefore, ferric-carboxylate complexes had likely a primary role in iron dissolution and $\mathrm{ROS}$ formation in the MIL-53(Fe) $/ \mathrm{H}_{2} \mathrm{O}_{2} / \mathrm{SR}$ AOP. The enhanced generation of ROS is reflected in the DOC removal presented in Figure 15 for both $\mathrm{Ph}$ and MTP experiments. Thus, despite the continuous leaching of BDC linker from MIL$53(\mathrm{Fe}), \mathrm{DOC}$ decreased significantly during the first hour of irradiation. At longer times when $\mathrm{H}_{2} \mathrm{O}_{2}$ was completely consumed (see Figure 16), ROS generation would decrease drastically and, as a result, DOC increased because the accumulation of $\mathrm{H}_{2} \mathrm{BDC}$ and oxidation products in solution.

From the discussion above, it is clear that homogeneous photo-Fenton-like reactions might likely be a leading oxidation mechanism in the MIL-53(Fe) $/ \mathrm{H}_{2} \mathrm{O}_{2} / \mathrm{SR}$ process. $\mathrm{Fe}(\mathrm{III}) / \mathrm{H}_{2} \mathrm{O}_{2} / \mathrm{SR}$ runs were carried out to provide experimental proof of such contribution to $\mathrm{Ph}$ and MTP degradation. Figure 15 shows that the removal rates of $\mathrm{Ph}$ and MTP by $\mathrm{Fe}(\mathrm{III}) / \mathrm{H}_{2} \mathrm{O}_{2} / \mathrm{SR}$ were only slightly lower than those observed in the corresponding heterogeneous runs (i.e., MIL-53(Fe) $/ \mathrm{H}_{2} \mathrm{O}_{2} / \mathrm{SR}$ ) despite the relatively low concentration of $\mathrm{Fe}(\mathrm{III})$ used (i.e., $0.5 \mathrm{mg} \mathrm{L}^{-1}$ ). Moreover, DOC removals in homogeneous photo-Fenton runs followed similar trends than in heterogeneous runs during the first hour of reaction, when $\mathrm{H}_{2} \mathrm{O}_{2}$ was still present. After that time, very low concentration of $\mathrm{H}_{2} \mathrm{O}_{2}$ remained in solution but further DOC removal was observed in the $\mathrm{Fe}(\mathrm{III}) / \mathrm{H}_{2} \mathrm{O}_{2} / \mathrm{SR}$ runs, likely due to oxidation by ROS produced through reactions (25) to (27).

\section{Materials and Methods}

\subsection{Materials}

All solvents and reagents were used as received without further purification. Iron (III) chloride 6-hydrate ( $>97 \%$, CAS number 10025-77-1, Panreac, Barcelona, Spain), 1,4benzenedicarboxylic acid (terephthalic acid, H2BDC) (98\%, CAS number 100-21-0, SigmaAldrich, St. Louis, MO, USA) and N,N-Dimethylformamide (DMF) (99\%, CAS number 6812-2, Panreac, Spain) were used in the synthesis of MIL-53(Fe). Metoprolol tartrate ( $>97 \%$, CAS number 56392-17-7, Sigma-Aldrich, Spain) and phenol (>97\%, CAS number 604-00100-7, Sigma-Aldrich, Spain) were selected as organic water pollutants in photodegradation 
runs. Hydrogen peroxide (30\% w/v, CAS number 7722-84-1, Panreac, Spain), potassium persulfate ( $>99 \%$, CAS number 7727-21-1, Sigma-Aldrich, Spain) and ozone were used in some MIL-53(Fe) mediated photocatalytic tests. Ozone was produced in situ from pure oxygen by an ozone generator (Anseros Ozomat, COM-AD-02 model, Tübingen, Germany) and its concentration in the gas stream was measured with an Anseros Ozomat GM-6000 Pro gas analyzer. All solutions were prepared in ultrapure water (Milli-Q Academic, Millipore, 18.2 M $\Omega \cdot \mathrm{cm}$, Merck, Darmstadt, Germany).

\subsection{Synthesis of MIL-53(Fe)}

MIL-53(Fe) was prepared using a solvothermal method adapted from the literature [75]. A mixture of $\mathrm{FeCl}_{3} \cdot 6 \mathrm{H}_{2} \mathrm{O}(10 \mathrm{mmol}, 2.7 \mathrm{~g}), \mathrm{H}_{2} \mathrm{BDC}(10 \mathrm{mmol}, 1.66 \mathrm{~g})$ and DMF $(50 \mathrm{~mL}$ ) were stirred at room temperature for $30 \mathrm{~min}$. Then, the mixture was introduced into a $125 \mathrm{~mL}$ Teflon-lined stainless steel autoclave (Parr Instrument Company, Moline, $\mathrm{IL}$, USA), which was placed in an oven (P-Selecta, Spain) to be heated at $20{ }^{\circ} \mathrm{C} \cdot \mathrm{min}^{-1}$ up to $150{ }^{\circ} \mathrm{C}$ and held at this temperature for $65 \mathrm{~h}$. After that, the reaction vessel was removed from the oven and allowed to cool down to room temperature before recovering the solid by centrifugation at $4000 \mathrm{rpm}$ for $5 \mathrm{~min}$. The solid was thoroughly washed, first with methanol and then repeatedly with Milli-Q water. Then, it was suspended in $200 \mathrm{~mL}$ of Milli-Q water overnight to remove substances still retained in the pores. Finally, the obtained solid sample was dried in a rotary evaporator at $75^{\circ} \mathrm{C}$ under vacuum and then in an oven at $100^{\circ} \mathrm{C}$ for $1 \mathrm{~h}$. The as-prepared catalyst was stored in a glass desiccator until further use.

\subsection{Characterization of MIL-53(Fe)}

Powder X-ray diffraction (XRD) was carried out on a Bruker D8 Advance diffractometer (Bruker Corp., Madrid, Spain) with $\mathrm{Cu} K \alpha$ radiation $(\lambda=0.1541 \mathrm{~nm})$. The XRD patterns were recorded in the $2 \theta$ range of $5-30^{\circ}$ at a scan rate of $0.02 \mathrm{~s}^{-1}$ and time of accumulation of $1 \mathrm{~s}$ per point. Attenuated total reflectance mode Fourier transform infrared transmission spectra (ATR-FTIR) were recorded in a Nicolet iS10 apparatus (ICSA, Barcelona, Spain) using $\mathrm{KBr}$ pellets containing about $10 \mathrm{mg}$ of sample. The spectra were recorded in the wavenumber $550-4000 \mathrm{~cm}^{-1}$ range at a resolution of $1 \mathrm{~cm}^{-1}$. The BET surface area and porous structure of the synthesized MIL-53(Fe) were determined from $\mathrm{N}_{2}$ adsorptiondesorption isotherms obtained at $-196{ }^{\circ} \mathrm{C}$ on an Autosorb 1 apparatus (Quantachrome Instruments, Boynton Beach, FL, USA). Prior to the analysis, the sample was outgassed in vacuum $\left(<10^{-4} \mathrm{~Pa}\right)$ at $150{ }^{\circ} \mathrm{C}$ for $10 \mathrm{~h}$. The morphology of samples was examined with a Hitachi S-4800 field-emission scanning electron microscope (Hitachi, Düsseldorf, Germany) Thermogravimetric analysis mass spectrometry (TGA-MS) was carried out on a thermobalance (STA 449 F3 Jupiter ${ }^{\circledR}$, Netzsch, Weimar, Germany) coupled with a spectrometer (QMS 403D Aëolos III, Netzsch, Germany) from 40 to $950{ }^{\circ} \mathrm{C}$ using $50 \mathrm{~mL} \mathrm{~min}^{-1}$ of $\mathrm{Ar} / \mathrm{O}_{2}$ mixture $(80 / 20 \mathrm{v} / \mathrm{v})$ at a heating rate of $10^{\circ} \mathrm{C} \mathrm{min}^{-1}$. UV-vis diffuse reflectance spectroscopy (UV-vis-DRS) measurements were carried out with a UV-vis-NIR Cary 500 spectrophotometer (Varian-Agilent Technologies, Palo Alto, CA, USA) equipped with an integrating sphere device. Carbon and hydrogen contents of the MOF were determined using an elemental analyzer (TruSpec Micro, LECO Instrument, Madrid, Spain) while iron content was analyzed by wavelength dispersive X-ray fluorescence (WDXRF, S8 Tiger, Bruker Corp., Madrid, Spain).

\subsection{MIL-53(Fe) Stability Experiments)}

Stability tests of MIL-53(Fe) in water were performed in a $300 \mathrm{~mL}$ borosilicate glass vessel provided with magnetic agitation and ports for gas inlet, gas outlet and liquid sampling. This vessel was placed in the chamber of a solar box (Suntest CPS+, Atlas Material Testing Technology LLC, Madrid, Spain) equipped with a $1500 \mathrm{~W}$ air-cooled Xe lamp. The overall irradiance $(\lambda=300-800 \mathrm{~nm})$ at the photoreactor level was measured with a UV-vis spectrometer (Black Comet C, StellarNet Inc., Tampa, FL, USA) to be $581.4 \mathrm{~W} \cdot \mathrm{m}^{-2}$. In some 
instances, cut-off filters were used to restrict radiation to the visible range $(\lambda=390-800 \mathrm{~nm})$. The temperature of the simulator chamber was controlled at either $25^{\circ} \mathrm{C}$ or $40^{\circ} \mathrm{C}$. Typically, the vessel was charged with $250 \mathrm{~mL}$ of Milli-Q water. If required, the initial $\mathrm{pH}$ of the solution was then adjusted to the desired value by adding aqueous solutions of $0.1 \mathrm{M}$ $\mathrm{H}_{2} \mathrm{SO}_{4}$ or $0.1 \mathrm{M} \mathrm{NaOH}$. Then, an amount of MIL-53(Fe) was added and the suspension was agitated by means of a magnetic stirrer. In some experiments, hydrogen peroxide or potassium persulfate was also added to the mixture. After that, the lamp of the solar box was turn on (if illumination was required) and, simultaneously, a $10 \mathrm{Lh}^{-1}$ gas flowrate of air or an oxygen-ozone mixture (ca. $6 \mathrm{mg} \mathrm{L}^{-1}$ ozone concentration) was bubbled into the vessel through a porous diffuser. Once the runtime was elapsed, the solid was separated from the solution by vacuum filtration and dried overnight in an oven at $100{ }^{\circ} \mathrm{C}$. The supernatant aqueous solution was analyzed for $\mathrm{pH}$, dissolved organic carbon (DOC), iron, $\mathrm{H}_{2} \mathrm{BDC}$ and short-chain carboxylic acids (SCCAs). The recovered solid was analyzed by XRD and ATR-FTIR.

\subsection{Photodegradation Experiments}

Photodegradation of aqueous solutions of Ph $\left(25 \mathrm{mg} \mathrm{L}^{-1}\right)$ or MTP $\left(50 \mathrm{mg} \mathrm{L}^{-1}\right)$ was carried out in the experimental device described above for MIL-53(Fe) stability tests. The procedure was also similar to that followed in stability tests though a 30-min dark stage (lamp switched off) was considered to allow for Ph or MTP adsorption onto the catalyst before starting the photodegradation stage [76]. Samples were periodically withdrawn from the reactor, filtered through $0.54 \mu \mathrm{m}$ PET membranes and analyzed for $\mathrm{pH}$, pollutant concentration (either Ph or MTP), DOC, $\mathrm{H}_{2} \mathrm{BDC}$ and iron. If hydrogen peroxide, potassium persulfate or ozone was used as oxidant, its concertation in samples was also measured. Blank runs (i.e., without radiation or without catalyst) were also carried out.

\subsection{Analytical Methods}

Liquid samples from stability and photodegradation runs were analyzed by different techniques: (i) $\mathrm{H}_{2} \mathrm{BDC}, \mathrm{Ph}$ and MTP concentrations were analyzed by an HPLC apparatus provided with a UV-vis detector set at $225 \mathrm{~nm}$ (HP 1100 Series chromatograph, Agilent Technologies, Santa Clara, CA, USA). A Kromasil C-18 column (5 $\mu \mathrm{m}, 150 \mathrm{~mm}$ length, $4 \mathrm{~mm}$ diameter) was used as stationary phase while the mobile phase consisted of a mixture of $0.1 \%$ vol. formic acid in ultrapure water (solvent A) and acetonitrile (solvent B) at a constant flowrate of $1 \mathrm{mLmin}^{-1}$. The mobile phase program used for the analysis was as follows: start at 20\% B; 0-6 min, linear gradient of B in A (20-27.5\% B); 6-7 min, hold at $27.5 \%$ B, $7-8 \mathrm{~min}$, linear gradient $(27.5-20 \% \mathrm{~B}) ; 8-9 \mathrm{~min}$, hold at $20 \% \mathrm{~B}$. The retention times were $3.4 \mathrm{~min}\left(\mathrm{H}_{2} \mathrm{BDC}\right), 4.1 \mathrm{~min}(\mathrm{MTP})$ and $6.5 \mathrm{~min}(\mathrm{Ph})$. (ii) DOC was analyzed with a Shimadzu apparatus (TOC-V CSH model). (iii) Some SCCAs (e.g., oxalate, acetate, malate, formate, propionate, pyruvate, tartrate) were analyzed by ion chromatography using a Metrohm apparatus (Madrid, Spain) (881 Compact IC Pro model) provided with suppressor and conductivity detector. A MetroSep A Supp 5 column (150 mm length, $4 \mathrm{~mm}$ diameter), thermoregulated at $45{ }^{\circ} \mathrm{C}$, was used as stationary phase. A $0.7 \mathrm{mLmin}^{-1}$ flowrate of aqueous $\mathrm{Na}_{2} \mathrm{CO}_{3}$ (linear gradient program at $20 \mathrm{~min}$ from $0.6 \mathrm{mM}$ to $14.6 \mathrm{mM} \mathrm{Na} \mathrm{CO}_{3}$ in a 50-min analysis time and 10 min post-time equilibration) was the mobile phase. (iv) Iron concentration was determined by a photometric method based on the formation of a trizaine derivative using the Spectroquant Iron Test (Merck Millipore, Madrid, Spain). (v) Hydrogen peroxide was analyzed either by the cobalt carbonate method (conc. $<0.1 \mathrm{mg} \mathrm{L}^{-1}$ ) or by the titanium sulfate method (conc. $0.1-50 \mathrm{mg} \mathrm{L}^{-1}$ ) [77,78]. (vi) Persulfate concentration was measured by the iodometric titration method [79]. (vii) Ozone in aqueous solution was measured following the indigo trisulfonate colorimetric method [80]. (viii) Measurements of $\mathrm{pH}$ were made with a $\mathrm{pH}$-meter (Crison GLP21+). All UV-vis spectrophotometric determinations were recorded on a Thermo Spectronic Helios $\alpha$ device (Thermo Fisher Scientific, Waltham, MA, USA). 


\section{Conclusions}

The metal organic framework MIL-53(Fe) has been successfully prepared via a facile solvothermal method. The characterization of the resulting material is in good agreement with the literature. The as-prepared MIL-53(Fe) is relatively stable in water at $\mathrm{pH} 4$ but undergoes partial decomposition at alkaline conditions yielding $\mathrm{H}_{2} \mathrm{BDC}$ and amorphous oxyhydroxide species as hydrolysis products. At weakly acidic conditions $(\mathrm{pH}=4-5)$ the MOF shows increasing instability with temperature, exposure to UV-vis radiation and presence of oxidants such as ozone, persulfate and hydrogen peroxide. The photostability of MIL-53(Fe) under simulated solar radiation illumination in the presence of oxidants is compromised by the enhanced generation of ROS, which might attack the MOF structure leading to its decarboxylation (i.e, release of $\mathrm{H}_{2} \mathrm{BDC}$ and iron species to solution). The as-synthetized MIL-53(Fe) on its own shows limited photocatalytic activity for the removal of aqueous Ph and MTP under simulated radiation, though the removal efficiency can be greatly improved in the presence of added oxidants (i.e., ozone, persulfate or hydrogen peroxide). However, the enhanced removal of Ph and MTP cannot be primarily ascribed to the MIL-53(Fe) role as heterogeneous catalyst but to other reaction pathways such as direct attack of the oxidant (case of ozone) or the homogeneous catalytic effect of aqueous iron species (case of $\mathrm{H}_{2} \mathrm{O}_{2}$ ).

The findings of this study suggest that caution should be taken when proposing MIL-53(Fe) as a heterogeneous photocatalyst for the degradation of water pollutants. MOF photostability at actual reaction conditions is a critical issue that needs be considered before recommendation of the material for its utilization in photocatalytic treatments of water and wastewater.

Supplementary Materials: The following are available online at https:/ /www.mdpi.com/article/ 10.3390/catal11040448/s1, Table S1: Literature review on the performance of MIL-53(Fe) and MIL$53(\mathrm{Fe})$-based composites as visible photocatalysts for the degradation of aqueous organic pollutants.

Author Contributions: Conceptualization, P.M.Á. and A.R.; methodology, J.L.; validation, A.M.C.; investigation, J.L., A.M.C., A.R., P.M.Á.; data curation, J.L.; writing—original draft preparation, J.L.; writing-review and editing, A.R. and P.M.Á.; supervision, P.M.Á.; project administration, P.M.Á.; funding acquisition, P.M.Â. All authors have read and agreed to the published version of the manuscript.

Funding: This research was funded by the Ministerio de Economía y Competitividad (MINECO) and the Agencia Estatal de Investigación (AEI) of Spain through the project CTQ2015/64944, co-financed by the European Funds for Regional Development (FEDER, UE).

Acknowledgments: The authors thank the SAIUEX service of the University of Extremadura for the characterization analyses. Jorge López Gallego is also grateful to the Ministerio de Educación, Cultura y Deporte of Spain for an FPU grant (reference number FPU16/03629).

Conflicts of Interest: The authors declare no conflict of interest.

\section{References}

1. Robert, D.; Malato, S. Solar photocatalysis: A clean process for water detoxification. Sci. Total Environ. 2002, 291, 85-97. [CrossRef]

2. Gascón, J.; Corma, A.; Kapteijn, F.; Llabrés i Xamena, F.X. Metal Organic Framework Catalysis: Quo vadis? ACS Catal. 2014, 4, 361-378. [CrossRef]

3. Furakawa, H.; Cordova, K.E.; O'Keeffe, M.; Yaghi, O.M. The chemistry and applications of metal-organic frameworks. Science 2013, 341, 974-986. [CrossRef]

4. Llabrés i Xamena, F.X.; Corma, A.; García, H. Applications for metal-organic frameworks (MOFs) as quantum dot semiconductors. J. Phys. Chem. C 2007, 111, 80-85. [CrossRef]

5. Wang, C.; Li, J.; Lv, X.; Zhang, Y.; Guo, G. Photocatalytic organic pollutants degradation in metal-organic frameworks. Energy Environ. Sci. 2014, 7, 2831-2867. [CrossRef]

6. Bedia, J.; Muelas-Ramos, V.; Peñas-Garzón, M.; Gómez-Avilés, A.; Rodríguez, J.J.; Belver, C. A review on the synthesis and characterization of metal organic frameworks for photocatalytic water purification. Catalysts 2019, 9, 52. [CrossRef]

7. Zhang, X.; Wang, J.; Dong, X.; Lv, Y. Functionalized metal-organic frameworks for photocatalytic degradation of organic pollutants in environment. Chemosphere 2020, 242, 125144. [CrossRef] 
8. Wang, D.; Li, Z. Iron-based metal-organic frameworks (MOFs) for visible-light-induced photocatalysis. Res. Chem. Intermed. 2017, 43, 5169-5186. [CrossRef]

9. Sun, Q.; Liu, M.; Li, K.; Zuo, Y.; Han, Y.; Wang, J.; Song, C.; Zhang, G.; Guo, X. Facile synthesis of Fe-containing metal-organic frameworks as highly efficient catalysts for degradation of phenol at neutral pH and ambient temperature. CrystEngComm 2015, 17, 7160. [CrossRef]

10. Sun, Q.; Liu, M.; Li, K.; Han, Y.; Zuo, Y.; Wang, J.; Song, C.; Zhang, G.; Guo, X. Controlled synthesis of mixed-valent Fe-containing metal organic frameworks for the degradation of phenol under mild conditions. Dalton Trans. 2016, 45, 7952-7959. [CrossRef]

11. Gao, C.; Chen, S.; Quan, X.; Yu, H.; Zhang, Y. Enhanced Fenton-like catalysis by iron-based metal organic frameworks for degradation of organic pollutants. J. Catal. 2017, 356, 125-132. [CrossRef]

12. Li, X.; Guo, W.; Liu, Z.; Wang, R.; Liu, H. Fe-based MOFs for efficient adsorption and degradation of acid orange 7 in aqueous solution via persulfate activation. Appl. Surf. Sci. 2016, 369, 130-136. [CrossRef]

13. Pu, M.; Guand, Z.; Ma, Y.; Wan, J.; Wang, Y.; Brusseau, M.L.; Chi, H. Synthesis of iron-based metal-organic framework MIL-53 as an efficient catalyst to activate persulfate for the degradation of Orange $\mathrm{G}$ in aqueous solution. Appl. Catal. A Gen. 2018, 549, 82-92. [CrossRef]

14. Yu, D.; Wu, M.; Hu, Q.; Wang, L.; Lv, C.; Zhang, L. Iron-based metal-organic frameworks as novel platforms for catalytic ozonation of organic pollutant: Efficiency and mechanism. J. Hazard. Mat. 2019, 367, 456-464. [CrossRef]

15. Du, J.J.; Yuan, Y.P.; Sun, J.X.; Peng, F.M.; Jiang, X.; Qiu, L.G.; Xie, A.J.; Shen, Y.H.; Zhu, J.F. New photocatalysts based on MIL-53 metal-organic frameworks for the decolorization of methylene blue dye. J. Hazard. Mater. 2011, 190, 945-951. [CrossRef]

16. Ai, L.; Zhang, C.; Li, L.; Jiang, J. Iron terephthalate metal-organic framework: Revealing the effective activation of hydrogen peroxide for the degradation of organic dye under visible light irradiation. Appl. Catal. B Environ. 2014, 148-149, 191-200. [CrossRef]

17. Zhang, Y.; Li, G.; Lu, H.; Lv, Q.; Sun, Z. Synthesis, characterization and photocatalytic properties of MIL-53(Fe)-graphene hybrid materials. RSC Adv. 2014, 4, 7594-7600. [CrossRef]

18. Zhang, C.; Ai, L.; Jiang, J. Graphene hybridized photoactive iron terephthalate with enhanced photocatalytic activity for the degradation of rhodamine B under visible light. Ind. Eng. Chem. Res. 2015, 54, 153-163. [CrossRef]

19. Zhang, C.; Ai, L.; Jiang, J. Solvothermal synthesis of MIL-53(Fe) hybrid magnetic composites for photoelectrochemical water oxidation and organic pollutant photodegradation under visible light. J. Mater. Chem. A 2015, 3, 3074-3081. [CrossRef]

20. Trinh, N.D.; Hong, S. Photocatalytic decomposition of methylene blue over MIL-53(Fe) prepared using microwave-assisted process under visible light irradiation. J. Nanosci. Nanotechnol. 2015, 15, 5450-5454. [CrossRef]

21. Liang, R.; Jing, F.; Shen, L.; Qin, N.; Wu, L. MIL-53(Fe) as a highly efficient bifunctional photocatalyst for the simultaneous reduction of $\mathrm{Cr}(\mathrm{VI})$ and oxidation of dyes. J. Hazard. Mater. 2015, 287, 364-372. [CrossRef]

22. Panda, R.; Rahut, S.; Basu, J.K. Preparation of a $\mathrm{Fe}_{2} \mathrm{O}_{3} / \mathrm{MIL}-53(\mathrm{Fe})$ composite by partial thermal decomposition of MIL-53(Fe) nanorods and their photocatalytic activity. RSC Adv. 2016, 6, 80981-80985. [CrossRef]

23. Gao, Y.; Yu, G.; Liu, K.; Deng, S.; Wang, B.; Huang, J.; Wang, Y. Integrated adsorption and visible-light photodegradation of aqueous clofibric acid and carbamazepine by a Fe-based metal-organic framework. Chem. Eng. J. 2017, 330, 157-165. [CrossRef]

24. Gao, Y.; Li, S.; Li, Y.; Yao, L.; Zhang, H. Accelerated photocatalytic degradation of organic pollutant over metal-organic framework MIL-53(Fe) under visible LED light mediated by persulfate. Appl. Catal. B Environ. 2017, 202, 165-174. [CrossRef]

25. Araya, T.; Jia, M.; Yang, J.; Zhao, P.; Cai, K.; Ma, W.; Huang, Y. Resin modified MIL-53 (Fe) MOF for improvement of photocatalytic performance. Appl. Catal. B Environ. 2017, 203, 768-777. [CrossRef]

26. Feng, X.; Chen, H.; Jiang, F. In-situ ethylenediamine-assisted synthesis of a magnetic iron-based metal-organic framework MIL-53(Fe) for visible light photocatalysis. J. Colloid Interface Sci. 2017, 494, 32-37. [CrossRef] [PubMed]

27. Hu, L.; Deng, G.; Lu, W.; Pang, S.; Hu, X. Deposition of CdS nanoparticles on MIL-53(Fe) metal-organic framework with enhanced photocatalytic degradation of RhB under visible light irradiation. Appl. Surf. Sci. 2017, 410, 401-413. [CrossRef]

28. Han, Y.; Bai, C.; Zhang, L.; Wu, J.; Meng, H.; Xu, J.; Xu, Y.; Liang, Z.; Zhang, X. A facile strategy for fabricating AgI-MIL53(Fe) composites: Superior interfacial contact and enhanced visible light photocatalytic performance. New J. Chem. 2018, 42, 3799-3807. [CrossRef]

29. Wang, D.; Jia, F.; Wang, H.; Chen, F.; Fang, Y.; Dong, W.; Zeng, G.; Li, X.; Yang, Q.; Yuan, X. Simultaneously efficient adsorption and photocatalytic degradation of tetracycline by Fe-based MOFs. J. Colloid Interface Sci. 2018, 519, 273-284. [CrossRef]

30. Li, R.; Chen, Z.; Cai, M.; Huang, J.; Chen, P.; Liu, G.; Lv, W. Improvement of Sulfamethazine photodegradation by Fe(III) assisted MIL-53(Fe)/percarbonate system. Appl. Surf. Sci. 2018, 457, 726-734. [CrossRef]

31. Mei, W.; Li, D.; Xu, H.; Zan, J.; Sun, L.; Li, Q.; Zhang, B.; Wang, Y.; Xia, D. Effect of electronic migration of MIL-53(Fe) on the activation of peroxymonosulfate under visible light. Chem. Phys. Lett. 2018, 706, 694-701. [CrossRef]

32. Oladipo, A.A. MIL-53 (Fe)-based photo-sensitive composite for degradation of organochlorinated herbicide and enhanced reduction of Cr(VI). Process Saf. Environ. 2018, 116, 413-423. [CrossRef]

33. Liu, N.; Jing, C.; Li, Z.; Huang, W.; Gao, B.; You, F.; Zhang, X. Effect of synthesis conditions on the photocatalytic degradation of Rhodamine B of MIL-53(Fe). Mater. Lett. 2019, 237, 92-95. [CrossRef]

34. Liu, N.; Huang, W.; Tang, M.; Yin, C.; Gao, B.; Li, Z.; Tang, L.; Lei, J.; Cui, L.; Zhang, X. In-situ fabrication of needleshaped MIL-53(Fe) with $1 \mathrm{~T}-\mathrm{MoS}_{2}$ and study on its enhanced photocatalytic mechanism of ibuprofen. Chem. Eng. J. 2019, 359, 254-264. [CrossRef] 
35. Miao, S.; Zha, Z.; Li, Y.; Geng, X.; Yang, J.; Cui, S.; Yang, J. Visible-light-driven MIL-53(Fe)/BiOCl composite assisted by persulfate: Photocatalytic performance and mechanism. J. Photochem. Photobiol. A Chem. 2019, 380, 111862. [CrossRef]

36. Jiang, D.; Zhu, Y.; Chen, M.; Huang, B.; Zeng, G.; Huang, D.; Song, B.; Qin, L.; Wang, H.; Wei, W. Modified crystal structure and improved photocatalytic activity of MIL-53 via inorganic acid modulator. Appl. Catal. B Environ. 2019, 255, 117746. [CrossRef]

37. Tang, L.; Lv, Z.Q.; Xue, Y.C.; Xu, L.; Qiu, W.H.; Zheng, C.M.; Chen, W.Q.; Wu, M.H. MIL-53(Fe) incorporated in the lamellar $\mathrm{BiOBr}$ : Promoting the visible-light catalytic capability on the degradation of rhodamine B and carbamazepine. Chem. Eng. J. 2019, 374, 975-982. [CrossRef]

38. Cui, Y.; Nengzi, L.C.; Gou, J.; Huang, Y.; Li, B.; Cheng, X. Fabrication of dual Z-scheme MIL-53(Fe)/ $\alpha-\mathrm{Bi}_{2} \mathrm{O}_{3} / \mathrm{g}-\mathrm{C}_{3} \mathrm{~N}_{4}$ ternary composite with enhanced visible light photocatalytic performance. Sep. Purif. Technol. 2020, 232, 115959. [CrossRef]

39. Li, X.; Zeng, Z.; Zeng, G.; Wang, D.; Xiao, R.; Wang, Y.; Zhou, C.; Yi, H.; Ye, S.; Yang, Y.; et al. A “bottle-around-ship” like method synthesized yolk-shell $\mathrm{Ag}_{3} \mathrm{PO}_{4} @ \mathrm{MIL}-53(\mathrm{Fe})$ Z-scheme photocatalysts for enhanced tetracycline removal. J. Colloid Interface Sci. 2020, 561, 501-511. [CrossRef]

40. Liu, N.; Wang, J.; Wu, J.; Li, Z.; Huang, W.; Zheng, Y.; Lei, J.; Zhang, X.; Tang, L. Magnetic Fe ${ }_{3} \mathrm{O}_{4} @ M I L-53(F e)$ nanocomposites derived from MIL-53(Fe) for the photocatalytic degradation of ibuprofen under visible light irradiation. Mater. Res. Bull. 2020, 132, 111000. [CrossRef]

41. Wu, Q.; Liu, Y.; Jing, H.; Yu, H.; Lu, Y.; Huo, M.; Huo, H. Peculiar synergetic effect of $\gamma-\mathrm{Fe}_{2} \mathrm{O}_{3}$ nanoparticles and graphene oxide on MIL-53 (Fe) for boosting photocatalysis. Chem. Eng. J. 2020, 390, 124615. [CrossRef]

42. Zhang, Y.; Zhou, J.; Chen, J.; Feng, X.; Cai, W. Rapid degradation of tetracycline hydrochloride by heterogeneous photocatalysis coupling persulfate oxidation with MIL-53(Fe) under visible light irradiation. J. Hazard. Mater. 2020, 392, 122315. [CrossRef]

43. Deng, L.; Yin, D.; Khaing, K.K.; Xiao, S.; Li, L.; Guo, X.; Wang, J.; Zhang, Y. The facile boosting sunlight-driven photocatalytic performance of a metal-organic-framework through coupling with $\mathrm{Ag}_{2} \mathrm{~S}$ nanoparticles. New J. Chem. 2020, 44, 12568-12578. [CrossRef]

44. George, P.; Chowdhury, P. Enhanced photocatalytic performance of novel $\mathrm{S}_{2}$-doped MIL-53(Fe) under visible light. J. Alloys Compd. 2021, 850, 156578. [CrossRef]

45. Liang, R.; Shen, L.; Jing, F.; Qin, N.; Wu, L. Preparation of MIL-53(Fe)-reduced graphene oxide nanocomposites by a simple self-assembly strategy for increasing interfacial contact: Efficient visible-light photocatalysts. ACS Appl. Mater. Interfaces 2015, 7, 9507-9515. [CrossRef]

46. Huang, W.; Liu, N.; Zhang, X.; Wu, M.; Tang, L. Metal organic framework g- $\mathrm{C}_{3} \mathrm{~N}_{4} / \mathrm{MIL}-53(\mathrm{Fe})$ heterojunctions with enhanced photocatalytic activity for $\mathrm{Cr}(\mathrm{VI})$ reduction under visible light. Appl. Surf. Sci. 2017, 425, 107-116. [CrossRef]

47. Xia, Q.; Huang, B.; Yuan, X.; Wang, H.; Wu, Z.; Jiang, L.; Xiong, T.; Zhang, J.; Zeng, G.; Wang, H. Modified stannous sulfide nanoparticles with metal-organic framework: Toward efficient and enhanced photocatalytic reduction of chromium (VI) under visible light. J. Colloid Interface Sci. 2018, 530, 481-492. [CrossRef] [PubMed]

48. Liu, K.; Gao, Y.; Liu, J.; Wen, Y.; Zhao, Y.; Zhang, K.; Yu, G. Photoreactivity of metal-organic frameworks in aqueous solutions: Metal dependence of reactive oxygen species production. Environ. Sci. Technol. 2016, 50, 3634-3640. [CrossRef]

49. Chen, H.; Liu, Y.; Cai, T.; Dong, W.; Tang, L.; Xia, X.; Wang, L.; Li, T. Boosting photocatalytic performance in mixed-valence MIL-53(Fe) by changing Fe ${ }^{\mathrm{II}} / \mathrm{Fe}^{\mathrm{III}}$ ratio. ACS Appl. Mater. Interfaces 2019, 11, 28791-28800. [CrossRef]

50. Yu, D.; Wang, L.; Yang, T.; Yang, G.; Wang, D.; Ni, H.; Wu, M. Tuning Lewis acidity of iron-based metal-organic frameworks for enhanced catalytic ozonation. Chem. Eng. J. 2021, 404, 127075. [CrossRef]

51. Bezverkhyy, I.; Weber, G.; Bellat, J.P. Degradation of fluoride-free MIL-100(Fe) and MIL-53(Fe) in water: Effect of temperature and pH. Microporous Mesoporous Mater. 2016, 219, 117-124. [CrossRef]

52. Page, S.E.; Arnold, W.A.; McNeill, K. Terephthalate as a probe for photochemically generated hydroxyl radical. J. Environ. Monit. 2010, 12, 1658-1665. [CrossRef] [PubMed]

53. Chávez, A.M.; Rey, A.; López, J.; Álvarez, P.M.; Beltrán, F.J. Critical aspects of the stability and catalytic activity of MIL-100(Fe) in different advanced oxidation processes. Sep. Purif. Technol. 2021, 255, 117660. [CrossRef]

54. Millange, F.; Guillou, N.; Walton, R.I.; Grenèche, J.; Margiolaki, I.; Férey, G. Effect of the nature of the metal on the breathing steps in MOFs with dynamic frameworks. Chem. Commun. 2008, 130, 4732-4734. [CrossRef]

55. Nguyen, M.T.H.; Nguyen, Q.T. Efficient refinement of a metal-organic framework MIL-53(Fe) by UV-vis irradiation in aqueous hydrogen peroxide solution. J. Photochem. Photobiol. A 2014, 288, 55-59. [CrossRef]

56. Dhaka, S.; Kumar, R.; Deep, A.; Kurade, M.B.; Ji, S.W.; Jeon, B.H. Metal-organic frameworks (MOFs) for the removal of emerging contaminants from aquatic environments. Coord. Chem. Rev. 2019, 380, 330-352. [CrossRef]

57. Qian, X.; Yadian, B.; Wub, R.; Long, Y.; Zhou, K.; Zhu, B.; Huang, Y. Structure stability of metal-organic framework MIL-53 (Al) in aqueous solutions. Int. J. Hydrogen Energy 2013, 38, 16710-16715. [CrossRef]

58. Rodríguez, E.M.; Fernández, G.; Álvarez, P.M.; Hernández, R.; Beltrán, F.J. Photocatalytic degradation of organics in water in the presence of iron oxides: Effects of $\mathrm{pH}$ and light source. Appl. Catal. B Environ. 2011, 102, 572-583. [CrossRef]

59. Mateo, D.; Santiago-Protillo, A.; Albero, J.; Navalón, S.; Álvaro, M.; García, H. Long-term photostability in terephtalate metalorganic frameworks. Angew. Chem. Int. Ed. 2019, 58, 17843. [CrossRef] [PubMed]

60. Chávez, A.M.; Rey, A.; Beltrán, F.J.; Álvarez, P.M. Solar photo-ozonation: A novel treatment method for the degradation of water pollutants. J. Hazard. Mater. 2016, 317, 36-43. [CrossRef] [PubMed] 
61. Thiruvenkatachari, R.; Kwon, T.O.; Jun, J.C.; Balaji, S.; Matheswaran, M.; Moon, I.S. Application of several advanced oxidation processes for the destruction of terephthalic acid (TPA). J. Hazard. Mater. 2007, 142, 308-314. [CrossRef]

62. Fuentes, I.; Rodríguez, J.L.; Poznyak, T.; Chairez, I. Photocatalytic ozonation of terephtalic acid: A by-product-oriented decomposition study. Environ. Sci. Pollut. Res. 2014, 21, 12241-12248. [CrossRef] [PubMed]

63. Faust, B.S.; Zepp, R.G. Photochemistry of aqueous iron(III)-polycarboxylate complexes: Roles in the chemistry of atmospheric and surface waters. Environ. Sci. Technol. 1993, 27, 2517-2522. [CrossRef]

64. Rao, L.; Yang, Y.; Liu, X.; Huang, Y.; Chen, M.; Yao, Y.; Wang, W. Heterogeneous activation of persulfate by supporting ferric oxalate onto activated carbon fibers for organic contaminants removal. Mater. Res. Bull. 2020, 130, 110919. [CrossRef]

65. Zhang, G.; Wang, Q.; Zhang, W.; Li, T.; Yuan, Y.; Wang, P. Effects of organic acids and initial solution pH on photocatalytic degradation of bisphenol A (BPA) in a photo-Fenton-like process using goethite $(\alpha-\mathrm{FeOOH})$. Photochem. Photobiol. Sci. 2016, 15, 1046-1053. [CrossRef] [PubMed]

66. Rodríguez, E.M.; Fernández, G.; Álvarez, P.M.; Beltrán, F.J. $\mathrm{TiO}_{2}$ and Fe (III) photocatalytic ozonation processes of a mixture of emergent contaminants of water. Water Res. 2012, 46, 152-166. [CrossRef]

67. Hoigné, J.; Bader, H. Rate constants of reactions of ozone with organic and inorganic compounds in water-II: Dissociating organic compounds. Water Res. 1983, 17, 185-194. [CrossRef]

68. Benítez, F.J.; Acero, J.L.; Real, F.J.; Roldán, G. Ozonation of pharmaceutical compounds: Rate constants and elimination in various water matrices. Chemosphere 2009, 77, 53-59. [CrossRef]

69. Yang, J.; Zhu, M.; Dionysiou, D.D. What is the role of light in persulfate-based advanced oxidation for water treatment? Water Res. 2021, 189, 116627. [CrossRef]

70. Mei, Q.; Sun, J.; Han, D.; Wei, B.; An, Z.; Wang, X.; Xie, J.; Zhan, J.; He, M. Sulfate and hydroxyl radicals-initiated degradation reaction on phenolic contaminants in the aqueous phase: Mechanisms, kinetics and toxicity assessment. Chem. Eng. J. 2019, 373, 668-676. [CrossRef]

71. Tay, K.S.; Ismail, N.S.B. Degradation of $\beta$-blockers in water by sulfate radical-based oxidation: Kinetics, mechanism and ecotoxicity assessment. J. Environ. Sci. Technol. 2016, 13, 2495-2504. [CrossRef]

72. Wu, Y.; Prulho, R.; Brigante, M.; Dong, W.; Hanna, K.; Mailhot, G. Activation of persulfate by Fe(III) species: Implications for 4-tert-butylphenol degradation. J. Hazard. Mater. 2017, 322, 380-386. [CrossRef] [PubMed]

73. Chen, R.; Pignatello, J.J. Role of quinone intermediates as electron shuttles in Fenton and photoassisted Fenton oxidations of aromatic compounds. Environ. Sci. Technol. 1997, 31, 2399-2406. [CrossRef]

74. Olmez-Hanci, T.; Arslan-Alaton, I. Comparison of sulfate and hydroxyl radical based advanced oxidation of phenol. Chem. Eng. J. 2013, 22, 10-16. [CrossRef]

75. Al Haydar, M.; Abid, H.R.; Sunderland, B.; Wang, S. Metal organic frameworks as a drug delivery system for flurbiprofen. Drug Des. Dev. Ther. 2017, 11, 2685-2695. [CrossRef]

76. Quiñones, D.H.; Rey, A.; Álvarez, P.M.; Beltrán, F.J.; Plucinski, P.K. Enhanced activity and reusability of TiO 2 loaded magnetic activated carbon for solar photocatalytic ozonation. Appl. Catal. B Environ. 2014, 144, 96-106. [CrossRef]

77. Masschelein, W.; Denis, M.; Ledent, R. Spectrophotometric determination of residual hydrogen peroxide. Water Sewage Works 1977, 124, 69-72.

78. Eisenberg, G.M. Colorimetric determination of hydrogen peroxide. Ind. Eng. Chem. Res. 1942, 15, 327-328. [CrossRef]

79. Wahba, N.; El Asmar, M.F.; El Sadr, M.M. Iodometric method for determination of persulfates. Anal. Chem. 1959, 31, 1870-1871. [CrossRef]

80. Bader, H.; Hoigné, J. Determination of ozone in water by the indigo method. Water Res. 1981, 15, 449-456. [CrossRef] 